\title{
IDEAS A TENER EN CONSIDERACIÓN ANTE LA IRRUPCIÓN DE UN NUEVO MECANISMO DE CONTROL EMPRESARIAL: EL GPS
}

\author{
JORGE ARREDONDO PACHECO \\ Abogado
}

\begin{abstract}
RESUMEN: El presente artículo estudia la viabilidad de establecer un control permanente de los movimientos y desplazamientos del trabajador; semejante cuestión es la que he venido a denominar "monitorización permanente". Las interrogantes que se han tenido en consideración refieren a aspectos tales como, por ejemplo, si es jurídicamente defendible que el empresario pueda tomar conocimiento de todos los lugares que visita el trabajador, dónde se encuentra este en un momento determinado, las pausas que realiza y el tiempo que destina a estar en cada uno de ellos, etc.

Sin perjuicio de la legítima vigilancia que corresponde al empresario respecto de las actividades profesionales encomendadas, la hipótesis inicial parte de la siguiente interrogante: ¿Constituiría ello un seguimiento indebido del trabajador?, ¿cabe establecer alguna limitación al respecto?

$\mathrm{Y}$ es que, un control tal del trabajador por parte del empresario podría derivar en un control total de las acciones y movimientos que lleva a cabo el trabajador, más allá de las propias responsabilidades laborales. El GPS ideado para fines militares, al día de hoy es frecuentemente utilizado por la sociedad civil. El punto pasa entonces por determinar la procedencia de su incorporación como un mecanismo de control empresarial de las actividades de los trabajadores.
\end{abstract}

Palabras clave: GPS, facultad de control empresarial, derecho a la intimidad, derechos fundamentales de los trabajadores.

ABSTRACT: This article analyzes the feasibility of establishing a mechanism of permanent control of the displacements of workers during its labor shift, denominated "permanent monitoring". The key questions that arise throughout the analysis consider aspects such as the judicial right of the employer to control all the movements of their workers, the exact place where the employees are at any particular moment, the number and length of the breaks they take, among other.

Notwithstanding the legitimate right the employer has to supervise the professional activities entrusted to the employee, the initial hypothesis of this article arise from the following question: Does it represents an improper tracking of the worker? Is it appropriate to establish limitations in this regards? Such a control of the worker from the employer could result in the total control of the actions and movements carried out by the workers, beyond their professional responsibilities.

The GPS - developed initially for military tasks- is frequently used by the civil society and nowadays has been also used in business activities. The question is, hence, to analyze the legitimacy and under what conditions those control instruments could be allowed as monitoring mechanisms.

Key words: GPS, employer's control attribution, intimacy right, worker's fundamental rights

El presente artículo es una versión actualizada y resumida del Trabajo de Fin de Máster titulado "El control empresarial a través del GPS: Una aproximación al tema” defendido para la obtención del título de Máster Oficial en "Derecho del Trabajo y de la Seguridad Social a través de la jurisprudencia” de la Universidad Rey Juan Carlos (Madrid, España) en el mes de septiembre (2011). Por ello, el ordenamiento jurídico que sirvió como parámetro corresponde al español.

Un extracto de dicha Tesis fue publicado en la Revista Laboral Chilena correspondiente al mes de diciembre de 2010, pp. 85 y ss.

** Abogado, Máster en Derecho del Trabajo y de la Seguridad Social (Universidad Rey Juan Carlos, Madrid, España). Correo electrónico: jorge.arredondo.pacheco@gmail.com 


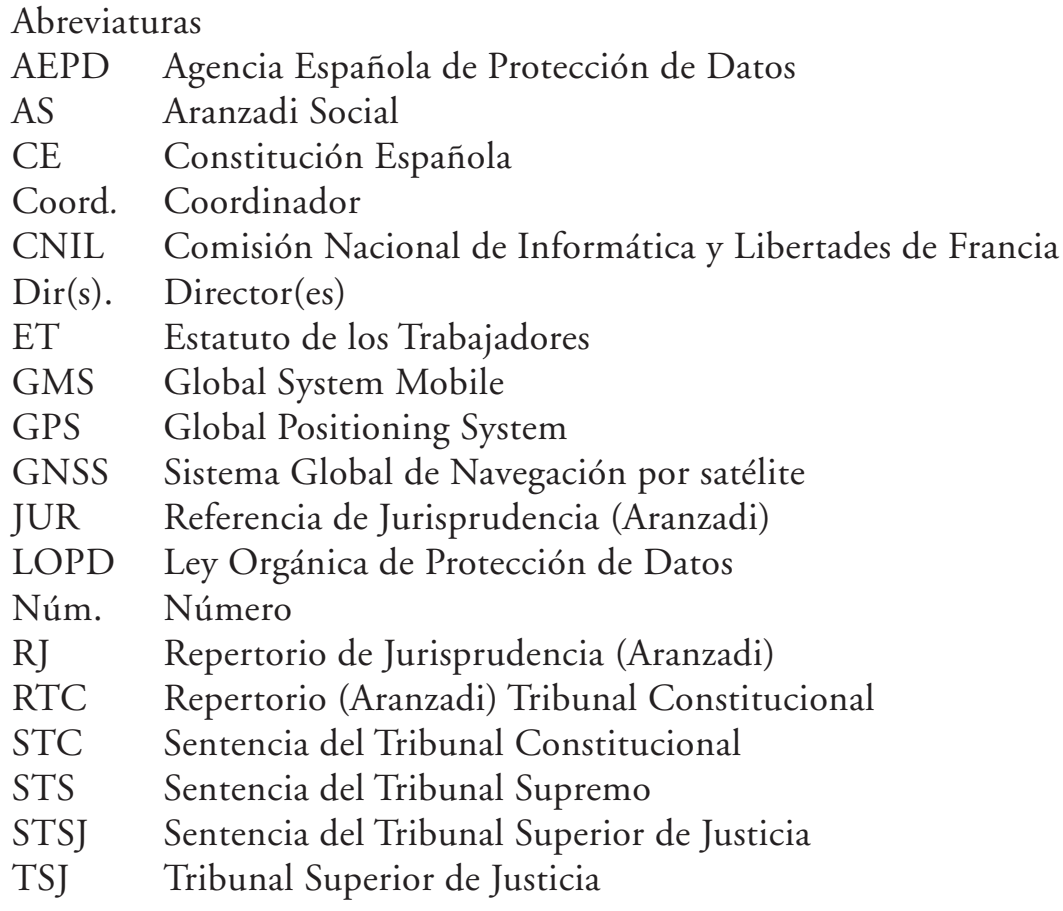

\section{IDEAS PRELIMINARES}

La implementación en las organizaciones empresariales de adelantos tecnológicos avanza día a día. Ello, en razón de que la globalización y la competencia que estos procesos traen aparejados requieren de empresas que mejoren sus estándares de eficiencia, permitiéndoles de esa forma estar vigentes y mantenerse alerta ante los cambios ${ }^{1}$.

Obviamente estas innovaciones no solo se utilizan para temas productivos, sino que permitirían moldearse a las necesidades que requieren los actores sociales, y en lo que aquí interesa, a los empresarios.

Y así ocurre con el caso del GPS (Global Positioning System), el cual corresponde a un adelanto científico, ideado para fines militares, pero que al día de hoy es frecuentemente utilizado por la sociedad civil. Este se caracterizaría porque permite tener un conocimiento (casi) exacto del lugar en que se encuentra. Lo cual, trasladado al ámbito empresarial, puede predicarse de los bienes propiedad del empresario como, por ejemplo, un coche o un camión, determinando con ello los movimientos que estos realizan. A ello cabe agregar la posibilidad de obtener esta información de forma inmediata ("en línea”) o, si es que así se prefiere, al final de la jornada de trabajo, pudiendo reconstruirse el plan de ruta ${ }^{2}$.

\footnotetext{
1 Para una comprensión de este fenómeno en las relaciones laborales vid. SEMPERE NAVARRO, A. V. y SAN MARTíN MAZZUCCONO, C. Nuevas tecnologías y relaciones laborales. Pamplona, Madrid: Aranzadi, 2002.

2 Simplemente a modo ejemplar, puede mencionarse el servicio que tiene a disposición, en Chile, la empresa Gesat, la cual "ofrece la contratación de un sistema de monitoreo permanente de su vehículo, mediante la instalación de un dispositivo GPS
} 
En este caso, lo "vigilado" es un instrumento de trabajo, cuestión que no presenta mayor problema. Sin embargo, el tema podría complicarse desde un punto de vista jurídico en razón de que la herramienta de trabajo requiere de la "conducción" de un ser humano (trabajador), con lo que sería factible tener acceso a toda la rutina ejercida por este en un día determinado, en qué lugar se detuvo a desayunar, a qué hora se hizo, y dónde una pausa de trabajo, cuánto tiempo tomo en ello, si se dirigió a algún lugar diferente al encomendado, etc.

Llegados a este punto cabría plantearse el siguiente interrogante: ¿Constituiría ello un seguimiento indebido del trabajador? Y si así fuese, ¿cabe establecer alguna limitación al respecto?

Pero aún más. Adviértase cómo la tecnología permite que al día de hoy incorporar esta innovación en teléfonos móviles (en cuyo caso se denomina GMS, Global Mobile System) o portátiles, por lo que la indivisibilidad que pudiese acontecer en la anterior hipótesis se recrudece para este caso. Si el trabajador está obligado a portar estas herramientas de trabajo, no es solo posible detectar el lugar en que aquellas se encuentran, sino de forma derivada, y dada en ocasiones la imposibilidad de su separación, dónde se encuentra el trabajador a cada instante y cuáles son las acciones de movimiento o permanencia que realiza ${ }^{3}$.

Por supuesto, en este breve comentario no se cuestiona la legítima capacidad del empresario para vigilar las actividades profesionales encomendadas. Sin embargo, resulta oportuno cuestionarse hasta qué punto es viable el establecimiento de un control permanente de los movimientos y desplazamientos del trabajador; esto es, de lo que hemos venido en denominar la "monitorización permanente". A este respecto, se plantean las interrogantes consistentes en si es jurídicamente defendible que el empresario pueda tener conocimiento de todos los lugares que visita el trabajador, dónde se encuentra este en un momento determinado, las pausas que realiza y el tiempo que destina a estar en cada uno de ellos, entre otros aspectos. Especialmente cuando dichas actividades no guardan una relación directa con la prestación de servicios laborales contratada.

El supuesto en el cual se está pensando al momento de elaborar estas interrogantes radica en aquellos trabajadores que ejecutan sus funciones principalmente fuera del recinto de la empresa, aparentemente bajo una mayor flexibilidad, ayudado con herramientas informáticas que permitirían esta mayor libertad, pero que, a su vez, admiten la posibilidad de realizar una vigilancia casi absoluta.

Así las cosas, el presente artículo posee un carácter intencionadamente provocativo, en el sentido de despertar preguntas, llamar la atención de situaciones que hoy en día suceden o que en un futuro cercano pudiesen ocurrir. Todo ello en el ánimo de alcanzar el

de rastreo satelital en su vehículo que emite señales que son recibidas en nuestra Central de Operaciones”. http://www.gesat.cl/ quienes\%20somos.html (Última consulta realizada el 18 de octubre de 2011).

3 A modo ejemplar, interesante resulta el artículo periodístico publicado por el periódico La Vanguardia, titulado "Trabajo pide a Schindler que deje de controlar a sus operarios con un chip", el cual causó bastante revuelo mediático por el mecanismo de control utilizado. Se puede consultar el artículo en: http://www.lavanguardia.com/economia/20111114/54238141779/ trabajo-pide-a-schindler-que-deje-de-controlar-a-sus-operarios-con-un-chip.html (Última consulta realizada el 19 de enero de 2012).

Un comentario jurídico a esta noticia puede encontrarse en http://eduardortega.blogcanalprofesional.es/2011/11/16/controlempresarial-\%C2\%BFdonde-esta-el limite/ (Última consulta realizada el 19 de diciembre de 2011). 
delicado equilibrio existente entre las legítimas competencias de control de que dispone el empresario y los derechos que asisten al trabajador. A su vez, se pretende tentativamente avanzar en algunas soluciones que pudiesen plantearse a fin de hacer compatibles el poder de control empresarial con el derecho a la intimidad del trabajador.

\section{EL GPS COMO UN NUEVO INSTRUMENTO DE CONTROL AL SERVICIO DEL EMPLEADOR}

\subsection{INNOVACIONES TECNOLÓGICAS EN EL CAMPO LABORAL: ESTADO ACTUAL DE LA CUESTIÓN}

Los avances tecnológicos traducidos al campo laboral son una realidad con la que debemos convivir en estos tiempos. Y ello, porque todo empresario, a fin de mejorar y ser más competitivo en el mercado, se encuentra permanentemente atraído a buscar alternativas novedosas y menos costosas para seguir vigente.

Dichas innovaciones, en lo que a los medios de control se trata, se han traducido en aquellos que simplemente se instauran para verificar los accesos de control a la organización productiva (como pudiesen ser, a modo ilustrativo, los controles biométricos) o, por otro lado, aquellos que tienen como finalidad exclusiva comprobar el cumplimiento de la prestación debida por el trabajador ${ }^{4}$.

En cualquier caso, claro queda que las nuevas técnicas de control no pueden quedar al margen de la regulación del Derecho del Trabajo, dado la indefensión en que se encontraría todo trabajador en esta situación. Pero tampoco el Derecho puede plantearse como un medio por el cual se impida el legítimo ejercicio del empresario de mejorar la forma en que se llevan a cabo las tareas que él encomienda 5 .

Ante esta nueva realidad tecnologizada a la que se ve enfrentada el Derecho, no es de extrañar que algunos autores planteen que el ordenamiento laboral debe reinventarse. Fundan esta afirmación en el sentido de que los indicios de laboralidad, propios de la realidad industrial de años anteriores, ya son parte del pasado, debiendo tenerse en consideración los nuevos elementos que caracterizarían una relación laboral. Así por ejemplo, en relación a la repercusión que las nuevas tecnologías tienen en la flexibilización de la dependencia, así como también en la intensificación del control empresarial, ha tenido ocasión de señalarse que:

\footnotetext{
4 Para leer un interesante artículo respecto a los controles biométricos vid. SELMA PENALVA, A. "El control de acceso por medio de huella digital y sus repercusiones prácticas sobre el derecho a la intimidad de los trabajadores", en: Aranzadi Socia: Revista Doctrinal, Vol. 3. España, 2010.

5 Pérez de los Cobos Orinuel, F. Nuevas tecnologías y relación de trabajo. Valencia, España: Tirant lo Blanch, 1990, p. 75, para quien "La transformación en acto y la previsible rompen, sin embargo, el equilibrio de intereses que, en materia de control de la prestación y respeto a la dignidad y privacidad del trabajador, ha regido hasta hoy en la relación de trabajo. Y lo hace, además, en un momento en el que cualquier obstáculo a la innovación tecnológica tiene un efecto económico mediato en la competitividad internacional. Es pues, el momento de imaginar fórmulas jurídicas que concilien las exigencias del respeto a la dignidad y a la privacidad del trabajador, con la renovación de los aparatos productivos".
} 
"ambos factores contribuyen a que al antiguo sistema indiciario deje de ser operativo para reconocer la naturaleza laboral de nuevas formas de prestar servicios dependientes. Por tanto, es ahora cuando necesariamente tienen que seleccionarse nuevos datos de hecho que, correctamente interpretados actúen como elementos indiciarios reveladores de la laboralidad de un vínculo controvertido"6.

$\mathrm{Y}$, más concretamente, ante esta nueva realidad sociolaboral se añade que:

"se hace entonces imprescindible definir un nuevo haz indiciario, más apto para dar respuestas a los problemas de identificación que se suscitan en el siglo XXI. Para ello es necesario previamente proponer y seleccionar una serie de elementos fácticos que aplicados en abstracto a una relación de naturaleza jurídica controvertida sean útiles para dilucidar su verdadero carácter"7.

Centrándonos en lo que a los instrumentos de control se trata, parece evidente que la realidad tecnológica ha llegado al punto de crear medios por los cuales el poder patronal se intensifica, corriendo serio peligro la intimidad del trabajador, en lo que podría denominarse como un control o monitorización permanente. Este, pudiera definirse como aquel por el cual el empresario sabe, o puede llegar a saber, los movimientos - no las conductas concretas- que realiza el asalariado, conocimiento que se puede tener en linea y en virtud de un seguimiento minuto a minuto, lo que implica un mayor grado de observación de las acciones llevadas a cabo no solo en el centro de trabajo, sino que también fuera de este.

Si antes el empleador contaba solo con lo que sus ojos le indicaban, ahora este poder de observación se extiende, no siendo necesario un control presencial, sino que a distancia y además a posteriori dada la posibilidad de reconstituir acciones pasadas ${ }^{8}$.

En este sentido debe tenerse en cuenta, además, que el ordenamiento jurídico laboral español no contempla una prohibición a la implementación de determinados medios de control, sino que se regula un muro de contención a objeto de evitar eventuales avasallamientos a los derechos fundamentales del trabajador. Como no podía ser de otro modo, esta realidad legislativa debe tenerse presente a objeto de lograr respuestas que compatibilicen tanto las innovaciones tecnológicas con el respeto irrestricto a los derechos constitucionales.

Y, es que, como con acierto ha establecido la doctrina científica:

\footnotetext{
6 Selma Penalva, A. "Las peculiaridades prácticas del control en la empresa”, en: Anales de Derecho, No 27, p. 96. Murcia, España: Universidad de Murcia, 2009.

7 Ibid., p. 100. Esta misma autora destaca como nuevos indicios a tener en consideración para configurar una relación como laboral: el lugar de trabajo como un signo neutro y no definitorio; el control de resultado de la actividad ejercida por el dependiente; la importancia de contar el trabajador con una casilla de correo electrónico institucional; el valor del programa informático facilitado por la empresa y la comunicación constante que pudiese existir entra las partes contratantes. Ibid., pp. 109 y ss.

8 Pérez de los Cobos Orihuel, F., op. cit. (n. 5), p. 72. Según este autor "las características de las nuevas tecnologías aplicadas a la industria están permitiendo, en efecto, primero una sustitución del control periférico, discontinuo y parcial realizado por la jerarquía humana, por un control centralizado y objetivo (en cuanto a que incorporado a la máquina) que se verifica en tiempo real, y en segundo término, la aparición de un nuevo y sofisticado tipo de control que consiste en la reconstrucción del perfil del trabajador, a través del almacenamiento y la reelaboración de una serie de datos aparentemente inocuos".
} 
"el legislador no previno los posibles conflictos que pudieran plantearse ante el uso de determinados sistemas de vigilancia y control, como la informática, y el derecho del trabajador a la protección de su dignidad. No calibró la profunda transformación que el uso de estas tecnologías podía comportar para las técnicas de control, tan profunda que ha llevado a calificar los otros medios de control (tele cámaras, escuchas telefónicas, etc.) como "pasado artesanal"”' 10.

En todo caso, antes de entrar de lleno en el análisis del GPS como nuevo mecanismo de control al servicio del empleador, parece oportuno efectuar con carácter previo una pequeña reseña de algunas opiniones que han sido dadas, por una parte de la doctrina como por cierta jurisprudencia en lo que refiere a la intensificación del poder de control -lo que se ha venido en denominar como control o monitorización permanente- y su conjugación con el respeto a la intimidad del trabajador. Todo ello con el ánimo de ilustrar cierto estándar de exigibilidad a la hora de implementar medios de control aparentemente intrusivos.

Sin ánimo de exhaustividad, a continuación se da noticia de las principales doctrinas sentadas en la materia:

1. En un primer momento se ha sostenido que "Si el contrato de trabajo... no comporta privación de los derechos fundamentales para el trabajador, pero sí su modulación, nada de extraño hay que así suceda en el caso del derecho a la intimidad: la empresa no puede acceder de manera absoluta al conocimiento de cuanto realiza su asalariado. Pero las cosas no son tan sencillas e incluso tan prudente aserto ha de ser razonado,..., al existir aparentes argumentos en contrario"11.

2. A propósito de las técnicas de control referidas a la asistencia y tiempos de incidencia de la prestación, se ha argumentado que "ello implica en nuestra opinión, la ilicitud en la inmensa mayoría de los casos, de todos aquellos sistemas de control que permitan un seguimiento minuto a minuto de la actividad del trabajador en su puesto de

\footnotetext{
Cardona Rubert, M. B. Informática y contrato de trabajo. Valencia, España: Tirant lo Blanch, 1990, p. 57.

10 Como con acierto ha indicado la doctrina "Sin duda, la introducción de las nuevas tecnologías en la empresa, además de cambiar de forma sustancial los modos y modelos de trabajo y producción, presenta en su influencia sobre el poder de dirección uno de sus manifestaciones "más vistosas", habida cuenta aquéllas están habilitando -cada vez más- medios sofisticados capaces de "intensificar" de forma decisiva -y en muchos casos hasta más allá de lo lícito- las posibilidades empresariales de fiscalización de la actividad laboral", agregándose, "No es ocioso recordar cómo las nuevas tecnologías de la información y la comunicación permiten formas de control nuevas y casi "ilimitadas" que, de facto (y, en muchos casos, en medio de un cuando menos inquietante silencio legal) están siendo utilizadas por los empleadores para intensificar las formas de conocimiento del comportamiento de los trabajadores, creando centros de "trabajo virtuales" en los cuales la profecía orweliana del gran hermano adquiere dimensiones laboralizadas ("el inmenso poder del ojo mecánico" empresarial) en las que la realidad vuelve a superar a la ficción". TASCÓN LÓPEZ, R. "Sobre la evolución de los límites del poder tecnológico de control empresarial en el caso español”, en: IX Congreso Europeo de Derecho del Trabajo y de la Seguridad Social. Friburgo, Alemania, 16-19 de septiembre de 2008. Artículo disponible en http://kongress-und-kommunikation.com/html/img/pool/Round_table_1_RodrigoLopez.pdf (Última consulta realizada el 30 de diciembre de 2011).

11 Sempere Navarro, A. V. y San Martín Mazzuccono, C., op. cit. (n. 1), p. 66. Ambos autores matizan posteriormente esta afirmación, apoyándose entre otras, en razones de índole económica, dada la titularidad del empresario como dueño de los medios que pone a disposición del trabajador.
} 
trabajo. No obstante, ha de tenerse en cuenta que, en ocasiones ese control minuto a minuto no es un extremo buscado de forma directa por el empresario, sino que es consecuencia inevitable del propio proceso productivo o de los útiles empleados en la prestación”. Reflexionado y planteando el autor, como una posible solución a estos casos, "replantear la aplicación del principio de proporcionalidad" 12 .

3. Por último, y en doctrina más reciente, se ha reflexionado que "los sistemas de navegación vía satélite son instrumentos que facilitan la conducción, pero que también pueden servir para indicar en todo momento cuál es la ubicación del vehículo. Ello se traduce,..., en un férreo control de los movimientos del trabajador, por lo que, del mismo modo, dado que no existe disposición administrativa que exija su incorporación al vehículo, podría entenderse que el control empresarial consistente en un permanente seguimiento del vehículo, supone una violación ilegítima de los derechos fundamentales del trabajador"13.

A su vez, por lo que respecta a la doctrina jurisprudencial y judicial española, existen numerosos fallos que se refieren a la inclusión de las nuevas tecnologías en la esfera laboral. Principalmente, los pronunciamientos jurisprudenciales se refieren a cuándo se incluyen estos instrumentos como medios de prueba, planteándose en esa etapa procesal el debate en cuanto a su procedencia o no en el respectivo juicio, atendido al posible carácter lesivo de derechos fundamentales.

Pero el debate de fondo, lo sustantivo de incorporar mecanismos de registro con carácter presumiblemente intrusivo o permanente (como pudiese ser el caso del GPS) ha estado, hasta el momento, presente en escasos pronunciamientos. La razón de ello pudiese radicar en "la ambigüedad de la normativa legal..., unida al rapidísimo crecimiento y desarrollo de nuevas formas de control amparadas en las tecnologías de la información y la comunicación", lo que ha provocado:

"que sean los Tribunales quienes queden abocados a establecer pautas de adecuación entre estos nuevos sistemas y los derechos fundamentales (inespecíficos), con lo cual "la criticable imprecisión legislativa obliga a una labor creadora, quasi legislativa,

12 Fernández Villazón, L. A. Las facultades empresariales de control de la actividad laboral. Pamplona, España: Aranzadi, 2003, p. 87.

En el mismo sentido vid. CARdona Rubert, M. B., op. cit. (n. 9), p. 65. Quien se refiere a controles intencionales y preterintencionales, diferenciados según la forma de realizar el control y a la finalidad perseguida: "Los controles intencionales, son aquellos que tienen, fundamentalmente, una función de control...”.

Los preterintencionales o defensivos, son "aquellos cuya utilización viene exigida por razones técnicas, productivas o de seguridad en el trabajo."

Esta autora es de opinión que "un control demasiado penetrante sobre el trabajador puede comportar la ruptura del equilibrio de intereses que en materia de control de la prestación y respecto a la intimidad del trabajador existe o debe existir en la relación de trabajo. Por ello, es necesario determinar cuáles son los límites al control informático del empresario y al sacrificio que la persona del trabajador ha de soportar, en aras de su inevitable posición de subordinación en el contrato”. Ibid., p. 65.

13 Agut García, C. "Las facultades empresariales de vigilancia y control sobre útiles y herramientas de trabajo y otros efectos de la empresa”, En: GARCíA Ninet, J. I. (Dir.) y DE Vicente PACHÉs, F. (Coord.). El control empresarial en el ámbito laboral. Valencia, España: CISS, 2005, p. 124. 
de los tribunales, capaz de propiciar, en ocasiones, notables contradicciones, lo cual provocará, a la postre, un notable grado de inseguridad jurídica", pero será "a partir de tales pronunciamientos de donde se pueda empezar a construir cualquier doctrina general, a posteriori, de las consecuencias hacia las causas" ${ }^{14}$.

Teniendo presente lo anterior, de las sentencias que se han dictado hasta la fecha referida a la incorporación de innovaciones tecnológicas en el seno de una organización productiva, merecen destacarse las siguientes argumentaciones:

1a. En sentencia del TSJ de la Comunidad Valenciana, a propósito de una política empresarial que tenía como objetivo mejorar la productividad de dos trabajadores, se expresa:

"Cabe señalar, de otra parte, que no hace falta para vulnerar la dignidad del trabajador que se les hubiera ofendido de palabra o "faltado al respeto", como alega el demandante, sino que es suficiente con el acoso y vacío sistemático por un tiempo prolongado a modo de "plan de seguimiento específico" a unos trabajadores de modo consciente y con las concretas circunstancias que en el presente caso se han dado. Una sociedad democrática exige que sus ciudadanos, y en concreto sus trabajadores no sean humillados, el afán de productividad no puede reducir las condiciones mínimas de dignidad del trabajador, que no tiene por qué soportar una presión planificada como la del presente supuesto en su contexto laboral" 15 .

Aun cuando no trata de ninguna herramienta de registro concreta, especialmente llamativo resulta la referencia a una politica de seguimiento.

$2^{a}$. Un segundo ejemplo de relevancia en este aspecto, lo constituye la opinión del Ministerio Fiscal en un proceso que estaba siendo conocido por el Tribunal Supremo. El caso particular es a propósito de la eventual corresponsabilidad del empleador en situaciones de acoso sexual efectuado entre compañeros de trabajo y el deber de diligencia que es exigible del primero. Lo destacable, es la opinión que efectúa el Ministerio Fiscal.

Así, este en su informe expresa que:

"el hecho de que dos personas de distinto sexo u orientación sexual trabajen en un mismo recinto en solitario, no puede llevar a pensar en todos y cada uno de los ries-

\footnotetext{
14 TASCÓN LÓPEZ, R., op. cit. (n. 10), p. 10.

Agrega el autor, "quizá resulte oportuno aclarar que la mayor parte de los pronunciamientos judiciales habidos en la materia se producen en el marco de la impugnación de una sanción (habitualmente un despido) impuesta por la empresa a un trabajador como consecuencia de un incumplimiento laboral acreditado a través de una prueba obtenida mediante un medio informático-tecnológico".

"En tal contexto, el tribunal se ve abocado a dilucidar si tal prueba es lícita para acreditar dicho incumplimiento (y por tanto declarar procedente la medida patronal) o, por el contrario, resulta lesiva de algún derecho fundamental del trabajador (habitualmente la intimidad o, en el caso específico del control del correo electrónico, el secreto de las comunicaciones), en cuyo caso, carece de validez ex art. 90 LPL. Más infrecuentes resultan los litigios (si acaso de carácter colectivo) mediante los cuales los trabajadores tratan de combatir directamente un medio de control empresarial a través del proceso especial de tutela de los derechos fundamentales (arts. 171 y ss. LPL). Ibid., pp. 10 y 11.

15 STSJ Comunidad Valenciana 25 septiembre 2001 (RJCA 2002, 548).
} 
gos potenciales que pudieran ocurrir, ya que entonces el empleador necesitaría sistemas de vigilancia permanentes que podrían atentar contra el derecho de intimidad de los trabajadores" 16 .

$3^{a}$. Por último, es preciso mencionar una sentencia del Tribunal Supremo, el cual conociendo de un nuevo sistema de control horario (lectura biométrica de la mano de los trabajadores) se refiere a la finalidad del medio puesto en operaciones. Así el Tribunal Supremo lo califica de plenamente legítimo atendido los fines perseguidos, y termina expresando a su respecto, que:

"no hay norma que prohíba el recurso a la tecnología escogida para realizar el control del cumplimiento del horario de trabajo. Su novedad o complejidad no la convierten en lesiva de los derechos fundamentales invocados. Y el posible desequilibrio que pudiera existir entre el uso de la biometría y ese control no es cuestión a dirimir jurisdiccionalmente en este proceso" 17 .

\subsection{EL GPS COMO NUEVO MECANISMO DE CONTROL}

\subsubsection{El GPS: breve descripción}

La invención del GPS constituye uno de los avances tecnológicos más importantes del último tiempo. Concebido en sus inicios estrictamente para usos militares, al día de hoy, se encuentra masificado en la sociedad.

En efecto, "en 1990 y 1991, en el transcurso de la Guerra del Golfo, las tropas aliadas se sirvieron por vez primera, de forma generalizada, de los receptores GPS portátiles. Nadie podía imaginar, en aquel momento, la expansión que el sistema iba a experimentar en los años siguientes, y las repercusiones tecnológicas y económicas para la industria occidental y, muy especialmente, para la norteamericana" 18 .

En términos sencillos, el GPS es un "sistema de localización, diseñado por el Departamento de Defensa de los Estados Unidos, con fines militares, para proporcionar estimaciones precisas de posición, velocidad y tiempo" 19 .

Este sistema de posicionamiento geográfico puede a su vez también estar inserto en teléfonos móviles, en cuyo caso se le denomina GSM.

Referido al funcionamiento y forma de trabajo del GPS se ha explicado que "la obtención y comunicación de la posición de un objeto (un vehículo o un teléfono normalmente, porque lo que se "geolocaliza" no es la persona sino el objeto que tenga instalado alguno de dichos sistema) se hace a través de señales emitidas por satélite; y en el caso del GSM, mediante la red de telefonía móvil digital y la señal emitida por el teléfono” 20 .

16 STS 15 diciembre 2008 (RJ 2009, 1612).

17 STS 2 julio 2007 (Sala de lo Contencioso Administrativo) (RJ 2007, 6598).

18 PUCH, C. Nuevo Manual de GPS. Introducción al sistema global de posición. Madrid, España: Desnivel, 2005, p. 9.

19 PÉREZ DEL PRADO, D. "Instrumentos GPS y poder de control del empresario", en: Revista de la contratación electrónica, No 107 , p. 51. España, 2009.

20 GoÑ SEIN, J.L. "Controles empresariales: geolocalización, correo electrónico, internet, videovigilancia y controles biométricos”, en: Justicia Laboral. Revista de Derecho del Trabajo y de la Seguridad Social, No 39, p. 21. España, 2009. 
Al funcionar de forma relacionada con la información que le proporcionan satélites, se logra una precisión casi exacta del lugar en que se encuentra el objeto monitoreado, así como también trazar rutas de desplazamientos eficientes, permitiendo en todo caso, siempre el seguimiento del artículo al cual se encuentra incorporado este adelanto tecnológico.

Lo anterior se logra en razón que el sistema funciona gracias a que "el GPS utiliza la red de 24 satélites, ubicados en una órbita media de alrededor de $20.000 \mathrm{~km}$, como puntos de referencia para calcular la posición exacta en cuestión de metros. De hecho, con tipos avanzados de GPS se podría conseguir localizar un objeto con errores posicionales de pocos metros" 21 .

Explicando más detalladamente la operatividad del sistema, se señala que:

"el sistema se compone de tres segmentos básicos, los dos primeros de responsabilidad militar: el llamado segmento espacio, formado por 24 satélites GPS con una órbita de $26.560 \mathrm{~km}$ de radio y un período de $12 \mathrm{~h}$; segmento control, que consta de cinco estaciones monitoras encargadas de mantener en órbita los satélites y supervisar su correcto funcionamiento, tres antenas terrestres que envían a los satélites las señales que deben transmitir y una estación experta de supervisión de todas las operaciones; y el segmento usuario, formado por las antenas y los receptores pasivos situados en tierra. Los receptores, a partir de los mensajes que provienen de cada satélite, calculan distancias y proporcionan una estimación de posición y tiempo"22.

Dada las ventajas que presenta el sistema, no es inusual que su utilización se encuentre masificada en diversas áreas. Así por ejemplo en estudios de fenómenos atmosféricos, localización y navegación en regiones inhóspitas, modelos geológicos y topográficos, sistema de alarma automática, entre otros ${ }^{23}$.

Resalta en este aspecto, el uso que se le ha comenzado a dar en materia de control de flota de vehículos. En este sentido:

"la policía, los servicios de socorro, las centrales de taxi, los servicios de mensajerías, empresas de reparto, etc., organizan sus tareas optimizando los recorridos de las flotas desde una estación central. Algunas compañías ferroviarias utilizan ya el sistema GPS para localizar sus trenes, máquinas locomotoras o vagones, supervisando el cumplimiento de las señalizaciones" 24 .

Pero la evolución y revolución tecnológica no concluye ahí. No es ilusorio pensar que este adelanto científico el día de mañana pueda estar incorporado en otro tipo de aparatos. Ya se adelantó por un autor que "es solo cuestión de tiempo el que nuestros coches, nuestras

21 FERnÁNDEZ GARCíA, A. "Sistemas de geolocalización como medio de control del trabajador: un análisis jurisprudencial", en: Aranzadi, vol. 2, No 17, p. 4. España, 2010.

22 García, L.; Pozo Ruz, Ana; Ribeiro, A; Sandoval, F.; García-Alegre, M. C. "Sistema GPS: descripción, análisis de errores, aplicaciones y futuro", en: Mundo electrónico, No 306, p. 54. España, 2000

23 Ibid., pp. 57-58.

$24 \quad$ Ibid. p. 58. 
agendas electrónicas y nuestros teléfonos GSM incorporen un GPS, lo que, a buen seguro, multiplicará sus funciones" 25 .

A favor de ello, juega que ya es una realidad en estos tiempos, por ejemplo, el que se pueda encontrar GPS incorporados en camisetas. Tal es el caso de lo que ocurre con los jugadores de fútbol a quienes se les adosa el dispositivo con fines estrictamente deportivos y físicos ${ }^{26}$

Este escenario, puede llevar a pensar que el sistema ya se encontraría en condiciones para ser instalado en ropas de vestir. Por qué entonces no imaginar que pudiese ser aplicado en indumentaria de trabajo, tales como botas de trabajo, overoles, petos, cascos, chaquetas, etc.

Pero no solo eso, perfectamente entonces se podría suponer, por ejemplo, la viabilidad de que se utilice adosado a armas de fuego, a objeto de hacer un seguimiento del lugar en que estas se encuentran y, eventualmente, tener noticia de su uso. Asimismo, la inclusión del GPS en relojes, portátiles o cualquier otro instrumento de trabajo que se le proporcione al trabajador.

Este contexto, aumenta las posibilidades y aplicaciones para su uso, y, por qué no decirlo, también para su abuso en lo referido al control patronal ${ }^{27}$.

No debe perderse de vista que la masificación civil en la utilización de esta innovación va de la mano a su vez con el desarrollo de un proyecto, conocido como Galileo, el cual presenta dentro de sus ventajas que estará bajo control civil, lo que aumenta las posibilidades de buscar adaptaciones atendida la demanda que exista.

Galileo, en síntesis, es la "apuesta europea por disponer de un sistema propio y bajo control civil" 28 . En este sentido, se ha expresado que:

"sin duda cuando Galileo esté disponible la mejora en precisión, disponibilidad y continuidad que un receptor dual Galileo-GPS ofrecerá respecto a lo que conocemos hoy en día hará todavía más interesante la utilización de GNSS $^{29}$ en numerosas apli-

25 PUCH, C., op. cit. (n. 18), p. 9.

26 Vid. la nota periodística titulada Exitoso debut de sistema de GPS en los seleccionados, en la siguiente dirección de internet: http://diario.latercera.com/2011/06/20/01/contenido/deportes/4-73509-9-exitoso-debut-de-sistema-de-gps-en-los seleccionados.shtml (Última consulta realizada el 21 de junio de 2011).

27 De manera analógica, es preciso tener en consideración lo expresado por la doctrina para un sistema de control que presenta rasgos similares al GPS. Nos referimos a los RFID (identificadores por radiofrecuencia) mecanismo que en términos sencillos "surgen para perfeccionar la utilidad de los actuales códigos de barras facilitando el control de los productos y mercancías en general, pero en sus posibilidades se está ampliando a otros usos como el seguimiento e identificación de personas”. FARriols I SOLA, A. “Introducción”. En: AA.VV. La protección de datos de carácter personal en los centros de trabajo. Madrid (Cinca), 2006, p. 33.

En relación a los RFID, y en lo que es aplicable en nuestra opinión también para el caso del GPS, hay que tener en cuenta "el desarrollo de técnicas de "rastreo" de los movimientos y/o actos realizados por la persona ("tracking”). Esta tecnología permite localizar en cada momento los individuos que lo llevan en su ropa, su coche, etc., permitiendo una vigilancia constante. Esta nueva característica de los tratamientos masivos de datos, más allá de la elaboración de los perfiles de personalidad de los individuos, permite el seguimiento detallado de todos y cada uno de los pasos que da el individuo, supone un paso más en la vulneración de su vida privada, coaccionándole en el ejercicio de sus libertades más básica. Ibid., p. 34.

28 Cosmen-Schortmann, J. y MartíneZ-Olague, M. A. "Galileo, el sistema europeo de navegación por satélite", en: Carreteras. Revista técnica de la Asociación Española de la Carretera No 140, p. 115. España, 2005.

29 Sistema Global de Navegación por Satélite 
caciones que son realidades al día de hoy. Este es el caso de los sistemas de navegación, sistemas de gestión de flotas, localización de activos, antirrobos, etc. Otras que al día de hoy no son posibles resultarán viables y muchas otras que todavía no imaginamos surgirán"30 31 .

\subsubsection{El GPS como mecanismo de control. ¿Hacia la monitorización permanente del trabajador?}

Sobre la base de cuanto se acaba de indicar, ninguna duda cabe de que la incorporación del GPS (incluyendo en este concepto también al GMS) ya se encuentra presente en la realidad laboral; tanto como un instrumento al servicio de la eficiencia empresarial como en su vertiente de mecanismo de control de los trabajadores.

Pues bien, al encontrarse inserto en el contexto laboral, día a día se van produciendo inquietudes o dudas respecto al alcance que puede dársele a este medio, así como también a la información que este proporciona ${ }^{32}$.

Precisamente por ello, comienzan a producirse ya los primeros conflictos que llegan a conocimiento de los tribunales de justicia; conflictos en los que se cuestiona el uso que se ha hecho del GPS como medio de control de los trabajadores por parte del empresario. En este sentido, "son ya numerosas las sentencias que versan sobre la utilización de dispositivos GPS en el ámbito laboral cuando su utilización resulta una cuestión adyacente o colateral, una mera forma de prueba, pero muy pocas aún aquellas en el que el tema objeto de nuestro estudio constituye una alegación de fondo o principal" 33 . Siendo ello así, el estudio y análisis de este avance tecnológico merece ser apreciado a objeto de tener en consideración posibles soluciones ante una eventual colisión con los derechos fundamentales del trabajador; en específico, su intimidad personal.

De entrada, podría plantearse que el GPS, como mecanismo de control, no presenta un antecedente directo. En efecto, no existiría ningún medio que permitiese al empleador disponer de información al minuto de los desplazamientos que realiza un bien de su propiedad (coche, camión, portátil, etc.), fuera del recinto de la empresa. Tampoco existirían instrumentos que permitan conocer el movimiento de un trabajador cuando este se encuentra al exterior de la industria.

Con todo, se ha tratado de encontrar algún precedente similar a este nuevo sistema. Al respecto, se ha considerado como un posible antecedente de esta innovación la videovigilancia, expresando que "el seguimiento GPS puede verse como una forma evolucionada

\footnotetext{
30 Cosmen-Schortmann, J. y Martínez-Olague, M. A., op. cit. (n. 28), p. 118.

31 Cabe hacer presente que en el mes de noviembre del año 2011 fueron enviados los dos primeros satélites del sistema Galileo. Así fue señalado por la prensa. http://www.elpais.com/articulo/sociedad/primeros/satelites/Galileo/GPS/europeo/lanzaran/ manana/elpepusoc/20111018elpepusoc_16/Tes (Última consulta realizada el día 20 de enero de 2012).

32 A modo de ejemplo, se puede mencionar la nota periodística titulada "Sindicatos cuestionan decisión del alcalde Lantigua sobre GPS", que se refiere a un potencial conflicto socio-laboral suscitado en el ciudad norteamericana de Lawrence, Massachusetts, por la implementación de este instrumento como un mecanismo de control. Disponible en la siguiente dirección de Internet: http://hanleytimes.com/?p=3381 (Última consulta realizada el 14 de junio de 2011).

33 PÉreZ DEl Prado, D. “¿Puede el empresario controlar a sus trabajadores mediante dispositivos GPS? Algunas notas sobre el cómo, el dónde y el porqué”, en: Información Laboral. Jurisprudencia No 10, p. 12. España, 2009. En el mismo sentido TASCÓN LÓPEZ, R., op. cit. (n. 10), p. 10.
} 
de videovigilancia para aquellos casos en que la actividad desempeñada por el trabajador es móvil"34.

Así ocurre en lo referido al control de los trabajadores efectuado al interior de una organización productiva. En dicho marco desde hace ya un tiempo, el empleador cuenta con mecanismos de control audiovisuales, a través los cuales puede tener conocimiento de hechos que ocurren en ciertas dependencias de su propiedad.

Sin embargo, la limitación de este sistema se encuentra en que lo observado es específicamente lo que la cámara enfoca; por tanto, situaciones que se producen en espacios no filmados quedan eximidos de este poder de vigilancia.

Ello no ocurre con el GPS. Adviértase que no existirían espacios reservados no objetos de control, ya que el mecanismo sigue al bien objeto de supervisión, en la medida que se encuentra incorporado a este. Pero es que, incluso, más acentuado es el seguimiento en el caso de los móviles (GMS), puesto que al ser portado por el trabajador, permitiría, por ejemplo, tener noticia de los lugares que este visita en sus tiempos de descanso, en sus pausas de trabajo, dónde fuma un cigarrillo, etc.

En este último sentido, piénsese, por ejemplo, en un trabajador que tiene la obligación de prestar servicios en el interior de la organización portando el móvil que contiene el GMS y que desea ir en esos momentos de descanso a celebrar sus prácticas religiosas o concurrir a lugares que desea mantener en reserva puesto que corresponden a ideas o ideologías poco tradicionales. El resultado es que en esos instantes en que la prestación laboral no es cumplida, aun cuando está en su jornada de trabajo, no existiría la posibilidad de mantener reserva de acciones personales que no desean ser comunicadas al resto de la sociedad, atendida la conexión permanente a la que está sujeto.

Más gravoso resulta, incluso el escenario respecto de aquellos dependientes que no tienen la obligación de prestar sus servicios al interior de la empresa, sino que sus funciones son realizadas fuera de esta. En ese caso podría reconstruirse el día completo de los lugares en que se ha encontrado el trabajador así como el tiempo que ha destinado en estar cada uno de ellos.

Cuando el GPS se encuentra incorporado al camión o coche, estos problemas, en parte, pudiesen ser matizados. Y ello, por una razón práctica: el medio de transporte no sigue al trabajador, aquel puede quedar estacionado en cierto lugar y el trabajador desplazarse caminando sin estar conectado a la vigilancia patronal, sin embargo, ello no acontece cuando el GPS se encuentra en el móvil o portátil y este debe ser portado constantemente por el trabajador

La mencionada hipótesis rompería la "existencia de un ámbito propio y reservado frente a la acción y el conocimiento de los demás, necesarios, según las pautas de nuestra cultura, para mantener una calidad mínima de la vida humana” según la interpretación del derecho fundamental a la intimidad realizada por el Tribunal Constitucional ${ }^{35}$.

34 Ibid., p. 55.

35 Así por ejemplo, entre otras, en las SSTC 231/1988, de 2 diciembre 1988 (RTC 1988, 231), 99/1994, de 11 abril 1994 (RTC 1994, 99), 98/2000, de 10 abril 2000 (RTC 2000, 98) y 186/2000, de 10 julio 2000 (RTC 2000, 186). 
Teniendo claro las ideas precedentes, es que puede ir hablándose de la existencia de una monitorización permanente, una "“mano alargada” para el control absoluto de los operarios" 36 e, incluso, podría hablarse de la existencia de una "empresa panóptica" 37.

Esta nueva realidad es la que justifica la aparición de ciertas opiniones críticas al uso que puede dársele al GPS dado el carácter aparentemente invasivo (en principio de forma abstracta), en su uso de forma ilimitada.

En este aspecto se ha sostenido que:

"es evidente su incidencia en el derecho a la privacidad de los trabajadores, por lo que no parece que el empresario esté legitimado para adoptar cuando y como quiera este tipo de vigilancia tecnológica a distancia en virtud de la simple subordinación jurídica permanente del trabajador que caracteriza a la relación laboral y de la amplia facultad de control que le reconoce el artículo 20.3 ET. Esta lógica sería demasiado elemental, porque, dada la intensidad de este control tecnológico, supondría un salto cualitativo sobre las formas de control tradicionales hacia modelos orwellianos de control total"38.

Pero no solo ello. Para el caso de que el objeto monitoreado sea a la vez el medio por el cual se cumple la prestación laboral, se cumple -sin restricción alguna- una doble identidad. Esta se expresa en que el instrumento de control es a la vez la forma por la cual el trabajador debe cumplir la prestación de servicios encomendada. Dicho escenario produce una indivisibilidad entre la forma de cumplir lo pactado y el medio de vigilancia. En resumen, no hay escape posible a la indagación empresarial.

Esbozadas estas ideas, resultaría interesante retomar un punto expresado en líneas atrás. En efecto, se señaló en párrafos anteriores que la incorporación del GPS a la organización productiva, había producido la iniciación de ciertos conflictos judiciales, en los cuales se presentaba este como un medio de prueba del empresario para justificar ciertas decisiones extintivas de contratos de trabajo.

En este aspecto "las sentencias no consideran como suficiente medio de prueba los informes de trayecto que proporcionan los sistemas de geolocalización instalados en los vehículos de la empresa"39.

\footnotetext{
36 TASCÓn LÓpez, R. "El lento (pero firme) proceso de decantación de los límites del poder de control empresarial en la era tecnológica”, en: Aranzadi, No 17, 2007, p. 3.

37 Mercader Ugina, J. R. "Derechos Fundamentales de los trabajadores y nuevas tecnologías: ¿hacia una empresa panóptica?”, en: Relaciones Laborales, No 10, 2001, p. 667: “La idea de la fábrica panóptica, en la que la vigilancia es la segunda sombra que acompaña al trabajador, ha sido una constante en los teóricos de la organización de la empresa. Tanto Henri FORD (padre del fordismo) -que, insatisfecho con la vigilancia y control sobre sus trabajadores en la fábrica, creó un "Departamento sociológico" destinado a investigar el comportamiento de aquéllos en su tiempo libre-, como Frederick Winslow Taylor (padre del taylorismo) -que descubrió en su gestión científica del trabajo un funcionamiento operativo y cotidiano de la organización empresarial a través de una mayor capacidad de vigilancia- buscaron profundizar en el valor reflexivo del control: la gestión controla tanto a los trabajadores como a sí misma”.

38 GOÑI SEIN, J. L., op. cit. (n. 20), p. 22.

39 FERnÁNDEZ GARCÍA, A., op. cit. (n. 21), p. 5.
} 
Se admiten como medio para controlar la prestación debida, pero no constituyen el elemento definitorio en la ponderación que hace el tribunal para calificar la existencia de un incumpliendo grave y culpable de alguna obligación contractual. Para ello, se une a los antecedentes que entrega el GPS, la información proporcionada por partes de trabajo o lo que pudiese indicar un detective privado ${ }^{40}$.

En este punto, debe destacarse una de las primeras sentencias en las que el GPS tuvo un rol vital. Nos referimos a la Sentencia del Juzgado de lo Social, No 32, Madrid de 1 octubre 2003. En ella:

"se estimó procedente el despido de un trabajador, que ante la tardanza en los desplazamientos que efectuaba en su condición de montador y en el número de horas extraordinarias, se decidió la instalación de un sistema de control GPS en su vehículo para comprobar el tiempo dedicado a los desplazamientos así como el invertido en el descanso de los quince minutos del desayuno. No siendo considerada la medida adoptada por la parte empresarial como excesiva dadas las continuas advertencias de las que había sido objeto el trabajador" ${ }^{\prime 1}$.

Sin embargo, pronunciamientos judiciales que tratan la posible colisión de este novedoso mecanismo de control y el derecho a la intimidad de los trabajadores, hasta la fecha no existen fallos en este sentido por parte del Tribunal Supremo. Sin embargo, sí es posible encontrar supuestos en la jurisprudencia de los Tribunales Superiores de Justicia españoles. Así, se puede comentar un pronunciamiento del TSJ del País Vasco ${ }^{42}$.

Lo peculiar e interesante, en base a lo razonado sobre la distinción entre el GPS instalado en un medio de transporte o un móvil, es que el caso se refiera a esta última posibilidad. El proceso trata del despido disciplinario de un vigilante de seguridad (escolta) quien no prestó servicios en un día determinado, no obstante haber firmado un parte de trabajo que indicaba que sí había cumplido las funciones junto a otra compañera. Uno de los aspectos por los cuales el trabajador recurre de suplicación ante el TSJ, es porque considera que se ha vulnerado su derecho a la intimidad al incorporarse como medio de prueba la información que arroja el GPS que se encontraba en su teléfono móvil, situación que era desconoci-

40 En este sentido STSJ de Castilla-La Mancha 28 mayo 2009 (JUR 2009, 291078), Cataluña 15 enero 2008 (AS 2008, 1024), Madrid 18 mayo (PROV 2004, 236695), 28 diciembre 2004 (AS 2004, 4027) y 25 noviembre de 2008 (PROV 2009, 90353); País Vasco 7 septiembre 2010 (JUR 2010, 415913).

41 SANPedro Gullon, V. "Facultades empresariales de vigilancia y control en los centros de trabajo". En: GARCía NiNET, J. I. (Dir.) y De VICENTE PACHÉS, F. (Coord.). El control empresarial en el ámbito laboral. Valencia, España: CISS, 2005 , p. 100. Dicho pronunciamiento ha recibido críticas fundamentadas en que "un sistema de control de movimientos mediante GPS instalado en el vehículo de la empresa utilizado por el trabajador en sus desplazamientos puede ser considerado lícito, pues no existe otro mecanismo eficaz para verificar el cumplimiento de la prestación laboral al realizarse esta fuera del lugar de trabajo. Queda acogida, así, una preocupante doctrina que ya había sido utilizada con relativa frecuencia en cuanto hacía al control del empleado fuera del puesto a través de medios tradicionales, como solía ser mediante la contratación de un detective privado encargado de vigilar al operario". RODRÍGUEZ ESCANCIANO, S. "Vigilancia y control en la relación de trabajo: La incidencia de las nuevas tecnologías". En: AA.VV. La protección de datos de carácter personal en los centros de trabajo. Madrid (Cinca), 2006, p. 97.

42 STSJ País Vasco 2 de julio 2007 (JUR 2007, 365564). 
da por los trabajadores. En este aspecto, el Tribunal elabora el siguiente razonamiento en el fundamento jurídico segundo:

"siendo uno de los derechos fundamentales del trabajador el de intimidad personal que nuestra Constitución reconoce en su art. 18-1 y del que no queda privado en el ámbito de la relación laboral (art. 4-2-e ET), que desde luego queda afectado si el empresario utiliza un sistema de control del trabajo de sus empleados que se desarrolla fuera de sus dependencias a través de un sistema de localización permanente del teléfono móvil que se facilita como instrumento de trabajo, sin consentimiento ni conocimiento de aquéllos, máxime si estos han de tenerlo a su disposición en todo momento por estar sujetos a disponibilidad permanente, ya que si bien resulta un medio idóneo para controlar su labor (de lo que no le priva que pueda hacerse un uso que le impida realizar esa función, como sucede si el teléfono en cuestión no lo lleva consigo el trabajador), en modo alguno resulta necesario si tenemos en cuenta que el propio sistema de telefonía móvil siempre permite conocer ese dato y, por tanto, acceder a ese conocimiento con autorización judicial si concurren circunstancias que justifican una actuación de esa naturaleza, tan invasora del campo propio de la intimidad personal.

Esfera, esta, que ni tan siquiera desaparece durante la jornada laboral, en la que el trabajador mantiene un reducto en el que su empresario no puede penetrar si no resulta preciso por exigencias de la relación laboral, mediante un medio idóneo, necesario y suficientemente proporcionado al sacrificio de ese derecho fundamental".

Pese a esta declaración el Tribunal acaba desechando la existencia de una posible vulneración, al no acompañarse medios de prueba aptos, en esta instancia procesal, para fundamentar esta petición. A esto se suma que la decisión empresarial, en opinión del Tribunal, no solo tiene base en la información proporcionada por el GPS, sino que en otros elementos; rechazándose en definitiva el recurso de suplicación interpuesto por el trabajador.

Uno de los argumentos sobre el cual parece interesante detenerse, es en el referido a la posibilidad de acceder a la información del lugar exacto en que se encuentra el trabajador (monitorización permanente), lo que en el caso de los móviles, en parecer del TSJ, pudiese obtenerse previa autorización judicial. Al respecto, suena acertada la afirmación que hace la doctrina para este supuesto, la que ha expresado que:

"aunque fuera cierto, aunque pudiera averiguarse la ubicación exacta del trabajador únicamente con el teléfono móvil, más allá de los datos ofrecidos por este, relativos a su uso profesional o no, lo interesante jurídicamente hablando es precisamente que los datos ofrecidos por el GPS se obtienen sin autorización judicial, sin las garantías que esto supone. Esto abre la puerta al estudio jurisprudencial acerca de la legalidad de la forma de su obtención, así como su utilización como prueba en juicio; puerta que, en este caso, el Tribunal no abre" ${ }^{33}$.

43 Pérez del Prado, D., "Instrumentos... (n. 19), p. 67. 


\subsection{LimitaCiOnes a la MONITORIZACIÓN PERMANENTE DEL GPS. ENUNCIACIÓN DE POSIBLES SOLUCIONES}

Partiendo de la base de la legitimidad del empleador para adoptar la decisión de instaurar el GPS o GMS como un mecanismo de control en su organización productiva, corresponde ahora analizar algunas de las diferentes soluciones que han sido planteadas por la doctrina con el objeto de lograr la mayor armonía posible entre la instalación de este medio de control y el derecho a la intimidad de que es titular el trabajador.

En este sentido, pudiesen mencionarse las siguientes soluciones que a continuación se enuncian, las cuales podrían ser denominadas, según el caso, bajo un concepto o idea determinada.

\subsubsection{Indeterminación del trabajador controlado}

Al día de hoy muchas empresas han instaurado en sus dependencias controles de acceso o desplazamientos, mediante un mecanismo conocido como badges, esto es:

"tarjetas magnéticas que contienen un código identificador personal que, tras su introducción en un aparato dotado de un mecanismo lector y conectado a un ordenador central, permite el acceso a determinadas zonas de la empresa. Facilitan, así información suficiente para obtener un control detallado de los desplazamientos del trabajador" ${ }^{44}$.

Para esos supuestos, y con el objeto de lograr una cierta indeterminación del trabajador, y evitar que se efectúe un control personalizado de las acciones y movimientos que este realiza, la doctrina ha planteado como una posible solución el "sustituir el código individual por un código de grupo que se concederá a todos los trabajadores con funciones coincidentes" ${ }^{\prime 5}$. De esta forma, se tendería a proteger la esfera íntima del trabajador, en aquellos sectores productivos en que no exista una razón justificada para efectuar una memorización o identificación de ciertos sujetos.

Aplicando analógicamente la solución planteada por la doctrina ahora para el supuesto del GPS, pudiera pensarse en asignar un código grupal, en vez de uno individual, a todos aquellos trabajadores con funciones similares, o a cierto grupo de vehículos de la empresa que cubran determinados recorridos.

De esa forma se lograría cierta impersonalidad del medio de control, evitándose la posibilidad de reconstruir los movimientos y desplazamientos llevados a cabo por un trabajador en particular.

Esta respuesta no resuelve de modo tajante la problemática planteada, pero morigera la intervención empresarial en ciertas acciones personales que pudiera realizar el trabajador.

44 CARdona Rubert, M. B., op. cit. (n. 9), p. 75.

Referido a este instrumento, la doctrina ha expresado que "los más novedosos y sofisticados active badges que incluyen microprocesadores y transmisores de infrarrojos que permiten la identificación del sujeto y su control en la empresa, son otros ejemplos del permanente fluir electrónico. Alguien ha dicho que probablemente George Orwell estaría encantado porque su Big Brother alcanzaría a su través el tan deseado control total”. MERCADER UGinA, J. R., op. cit. (n. 37), p. 673.

45 Cardona Rubert, M. B., op. cit. (n. 9), p. 77. 


\subsubsection{Posibilidad de desconectarse}

Atendido el control permanente que permite efectuar el GPS y GMS, ha sido necesario ir también fijando límites o fronteras en cuanto a los momentos en los que debe regir este mecanismo de vigilancia. A este respecto, se ha planteado el derecho que tendría el trabajador para poder desconectarse del monitoreo que se le realiza, siendo esta una nueva respuesta o posibilidad para conjugar la discrecionalidad empresarial con el derecho a la intimidad del dependiente.

La existencia de este "derecho a la desconexión” ha surgido a propósito de la utilización de los teléfonos como un medio por el cual el empleador puede impartirle órdenes al trabajador en cualquier momento del día, aun fuera de su horario de trabajo ${ }^{46}$. En este sentido es preciso recordar lo señalado por la jurisprudencia, la cual ha expresado que:

"podrían resultar perjudicados los trabajadores en sus legítimos derechos e intereses, si se les obligara,..., a mantener una conexión ininterrumpida y en todo momento de sus teléfonos móviles con los de la empresa y los de todos sus clientes. Se sobrepasan las facultades normales y regulares de la empresa, en los términos previstos por el artículo 20 del Estatuto de los Trabajadores, si se obliga a los empleados a desarrollar su actividad profesional o a estar pendientes de recibir instrucciones en todo momento, incluso en las horas no coincidentes con la jornada de trabajo asignada a cada uno de ellos, pues a ese resultado se llegaría si se vieran forzados a mantener una atención constante a sus teléfonos móviles en todo momento..." 47.

A su turno, también se ha expresado como ejemplo lo ocurrido en Chicago, en donde "los empleados urbanos se negaron a utilizar móviles con GPS y obtuvieron el derecho a apagar los móviles durante los descansos y después del trabajo" ${ }^{4}$.

Otro caso es "el sindicatos de transportistas (que) acordó con la UPS que se utilizara el GPS solo para hacer un seguimiento de los envíos y no para controlar la disciplina de los trabajadores ${ }^{49}$ ". Esta posibilidad de desconectarse evita, en cierto modo, acceder a información de lo que realiza el trabajador en sus actividades extralaborales, pudiendo este reservarse la información de que en sus pausas concurre, por ejemplo, a una iglesia, santuario, mezquita u otros recintos que no desea divulgar.

\footnotetext{
46 Así, se ha expresado que "el empleador debería también entender que el teléfono móvil o el ordenador portátil no son normas derogatorias de la regulación de la jornada de trabajo; que el trabajador tiene derecho al descanso y no a que el móvil suene a cualquier hora para transmitir órdenes del empresario, etc.... Todo esto es lo que ha llevado a la doctrina francesa a acuñar el llamado "derecho a la desconexión": el trabajador podrá desconectar el móvil fuera de su jornada de trabajo y no tiene obligación ninguna de escuchar los mensajes hasta que la jornada se reanude". ALARCÓN CARACUEL, M.R. "La informatización y las nuevas formas de trabajo”. En: AA.VV. AlARCÓn CARACUEL, M.R. y ESTEBAN LEGARETA, R. (Coords.). Nuevas tecnologías de la información y la comunicación y Derecho del Trabajo. Bomarzo, 2004, p. 15.

47 Sentencia de la Audiencia Nacional 17 julio 1997 (AS\1997\3370).

${ }^{48}$ GRUBER, J. "Monitoring and the mobile workforce". Artículo disponible en Internet en la siguiente dirección: http:// workrights.us/wp-content/uploads/2011/02/gpsaba.pdf (Última consulta realizada el 26 de julio de 2011).

49 LANDSBergis, P. “¿Qué se debe hacer para prevenir los riesgos psicosociales en el trabajo?”, en: Archivos de prevención de riesgos laborales, vol. 11, № 1, p. 41. España, 2008.
} 
Esta solución permite uno de los resultados reclamados por parte de la doctrina. En concreto aquella que estima que:

"en el caso de los teléfonos móviles, sean personales o profesionales, tiene que haber algún dispositivo que permita desactivar el sistema fuera de las horas de trabajo; afirmándose con énfasis, que la geolocalización no debe servir para prolongar la subordinación del trabajador más allá del límite temporal determinado por la prestación pactada" 50 .

Como puede apreciarse, la incorporación de nuevas tecnologías en el contexto empresarial, va generando a su vez nuevos desafíos y respuestas. Y es que en un pasado reciente no hubiera podido imaginarse que el trabajador tuviera que realizar una acción (desconectarse) para poder llevar a cabo acciones de su vida privada fuera de la empresa.

Precisamente por ello, la doctrina ha compartido el razonamiento de la Comisión Nacional de Informática y Libertades de Francia (CNIL ${ }^{51}$ ) en cuanto a las obligaciones u acciones que se realizan fuera del recinto de la empresa. Este organismo

"ha hecho un esfuerzo por determinar los límites del grado de vigilancia permanente que los trabajadores deben aceptar en aras del interés del empresario de asegurar la localización de sus trabajadores cuando están fuera de la empresa, estableciendo una línea divisoria entre lo permisible y lo no permisible en función del tipo de actividad a realizar. La CNIL admite la vigilancia permanente tan solo cuando el trabajo consista en el desplazamiento, esto es, en conducir un vehículo, en cambio, la considera desproporcionada cuando el uso del vehículo sea un accesorio de su trabajo principal" 52 .

\subsubsection{Aplicación de estándares propios de la Ley Orgánica de Protección de Datos a la relación laboral}

A falta de normativa clara que resuelva el asunto, algunos autores han propuesto extraer los principios y estándares propios de la normativa de protección de datos personales y aplicarlos directamente a la relación laboral. Justifican esta medida en el hecho -sobre el

50 Goñi Sein, J.L., op. cit. (n. 20) p. 26. También De Vicente Pachés, F. "Las facultades empresariales de vigilancia y control en las relaciones de trabajo: Concepto y Fundamento. Una primera aproximación a las diversas formas de control empresarial”, en: Tribuna social: Revista de seguridad social y laboral No 157, p. 20. España, 2004. Este último autor se manifiesta en sentido similar al expresar que las nuevas tecnologías producen un control patronal mucho más "detallado, exhaustivo e implacable, indicando que esto ha motivado la necesidad de reconocer a los trabajadores un derecho a no estar constantemente vigilado, o dicho de otra forma, que se respete un grado razonable de libertad a la hora de determinar sus actuaciones ("licencias comportamentales"), dado que un control tan minucioso de la conducta del trabajador pudiera ser contraria a su dignidad, desde el momento en que se supone tratar al individuo, no como persona humana, sino como un engranaje más del aparato productivo".

51 Autoridad francesa en materia de protección de datos, cuya misión general "es la de velar para que la informática esté al servicio del ciudadano y no vulnere la identidad humana, ni los derechos humanos, la intimidad o las libertades individuales o públicas".

Para acceder a la página web en español de este organismo vid. la siguiente dirección de Internet: http://www.cnil.fr/espanol/

52 GOÑI SEIN, J.L., op. cit. (n. 20), p. 24 
cual no existe discusión- de que la calidad de trabajador no implica una renuncia a los derechos que como ciudadano le proporciona el ordenamiento jurídico.

En este sentido, se ha afirmado que:

"hay que dar un salto cualitativo y analizar, además, a la luz de la normativa de protección de datos porque no hay que desconocer que los datos de geolocalización transmitidos por un teléfono móvil a un operador en la medida en que están asociados a información de una persona física que se pueda identificar, implican tratamiento de datos personales incluido en el ámbito de aplicación de la Ley Orgánica de Protección de Datos" 53.

"En efecto, los dispositivos GPS no proporcionan datos íntimos ni confidenciales, pero sí datos protegibles de acuerdo con lo previsto en la LOPD, en tanto que identificativos de la posición geográfica de un determinado sujeto, en este caso el trabajador, a lo largo del tiempo" 54 .

Extrapolando la normativa de protección de datos a la sede laboral, parece que deberían existir unas determinadas obligaciones a cumplir por el empleador antes de la instauración del sistema GPS, como también posteriormente a que este se encuentre en funcionamiento; en particular, en lo que respecta al tratamiento de los datos obtenidos con el sistema de control. En cuanto a las obligaciones imperantes antes de la utilización del GPS, resulta ilustrativo el Informe 193/2008, de la Agencia Española de Protección de Datos55. En dicho informe se prescribe el necesario conocimiento que debe existir por parte del trabajador antes de que se implemente el mecanismo tecnológico ${ }^{56}$.

\footnotetext{
53 GOÑI SEIN, J.L., op. cit. (n. 20), p. 23. En el mismo sentido TASCÓN LÓPEZ, R., "Sobre la evolución... (n. 10), p. 36, quien señala "Muchas veces ha sido puesto de manifiesto cómo, dentro de un mundo en el que la información relativa a las personas circula a velocidades vertiginosas nunca antes pensadas - propiciando evidentes peligros para sus derechos fundamentales-, la relación laboral constituye un caldo de cultivo ideal para que el empresario -siempre inclinado a utilizar a favor suyo cualesquiera avances tecnológicos- lleve a efecto tratamientos de enormes cantidades de información sobre sus trabajadores, debiendo entonces resultar de aplicación la legislación sobre protección de datos personales en el intento por encontrar garantías adecuadas".

54 Pérez del Prado, D. “¿Puede... (n. 33), p. 10.

55 Dictado con ocasión de la consulta formulada por una empresa en la que se le planteaba cómo debía de procederse respecto al tratamiento de datos emitidos por el sistema de GPS instalado en los vehículos de trabajadores de la empresa y que tenía como función controlar los itinerarios que estos efectuaban durante la jornada laboral.

56 Interesante es la reflexión que realiza la doctrina al comparar la doctrina del Tribunal Supremo referida a las facultades del empleador para hacer revisión en los computadores de su propiedad que son utilizados por los dependientes de la empresa (sentencias de fecha 26 de septiembre de 2007 [RJ 2007, 7514] y de 8 de marzo de 2011 [RJ 2011, 932], así como las más reciente, que comentaremos más adelante de fecha 6 de octubre de 2011 [Recurso 4053/2010]) con lo expresado por la Agencia de Protección de Datos.

Así, se señala que "no deja de resultar curioso, a la vez que esperanzador, la coincidencia entre la línea marcada por la sentencia del Tribunal Supremo... y... la Agencia, pues ambas exigen que los sujetos controlados conozcan en todo momento que están siendo vigilados, lo cual mueve a pensar que la perspectiva correcta pasa más por la prevención de actividades ilícitas que en el posterior resarcimiento o sanción, algo mucho más acorde con los parámetros de un Estado Democrático de Derecho, en el cual la vigilancia y las restricciones de derechos fundamentales han de jugar tan solo un papel accesorio y complementario, en tanto permitan cumplir otras finalidades legítimas". TASCÓN LÓPEZ, R., “Sobre la evolución... (n. 10), p. 43.
} 
Así, si bien existiría una legitimación del empleador para aplicar este sistema (la Agencia no pone en duda este derecho) ello no excluye el cumplimiento del deber de informar, por parte del empresario previsto en el artículo 5.1 de la LOPD española, señalando que:

"Los interesados a los que se soliciten datos personales deberán ser previamente informados de modo expreso, preciso e inequívoco: a) De la existencia de un fichero o tratamiento de datos de carácter personal, de la finalidad de la recogida de estos y de los destinatarios de la información. b) Del carácter obligatorio o facultativo de su respuesta a las preguntas que les sean planteadas. c) De las consecuencias de la obtención de los datos o de la negativa a suministrarlos. d) De la posibilidad de ejercitar los derechos de acceso, rectificación, cancelación y oposición. e) De la identidad y dirección del responsable del tratamiento o, en su caso, de su representante" 57 .

Pero la doctrina ha avanzado aún más, puesto que se ha razonado que no solo sino que se satisface el requisito de la procedencia de instaurar mecanismos de control con el aviso previo que se pueda hacer a los trabajadores. En este sentido, es preciso tener en cuenta además ciertos principios básicos como, por ejemplo, el principio de la finalidad legítima, expresado en términos de que "debe haber un fin legítimo para la geolocalización que justifique la restricción que experimentan los trabajadores en sus derechos fundamentales. Se impone, pues, un criterio restrictivo en la adopción de estos dispositivos de vigilancia geográfica a distancia" 58 .

Junto a este principio básico, debe tenerse en cuenta también la transparencia, "que impone el deber de informar a los trabajadores de la existencia de tal mecanismo en el vehículo o teléfono móvil proporcionado por la empresa, así como de la finalidad de recogida de datos" 59 .

En fin, la incorporación de estas nuevas variables y principios en el razonamiento jurídico, es lo que ha llevado a plantear a algunos autores la necesaria reformulación del principio de proporcionalidad para ponderar los bienes jurídicos en juego. Este se constituiría en una nueva solución que proporciona la doctrina para resolver los novedosos problemas que plantea el asunto estudiado.

\footnotetext{
57 Informe 193/2008 de la Agencia Española de Protección de Datos. Disponible en la siguiente dirección de Internet: https://www.agpd.es/portalwebAGPD/canaldocumentacion/informes_juridicos/common/pdfs/20080193_Tratamiento-dedatos-de-GPS-en-veh-ii-culos.pdf (Última consulta realizada el 26 de julio de 2007).

58 GOÑI SEIN, J. L., op. cit. (n. 20), p. 24, quien considera que resulta legítimo el mecanismo de control "cuando sirve para garantizar la seguridad del empleado, de las mercancías o de los vehículos, o para ofrecer una mejor prestación de los medios en vehículos o para hacer un seguimiento y facturación de las prestaciones de transporte, pero no cuando se trata de hacer un seguimiento del tiempo de trabajo, salvo que no se pueda hacer de otro modo".

59 GoŃi SEIN, J. L., op. cit. (n. 20), p. 25. Para un estudio más detallado respecto de la aplicación de la normativa de protección de datos en la relación laboral, vid. GOÑI SEIN, J. L., La videovigilancia empresarial y la protección de datos personales. Pamplona, España: Thomsom Civitas, 2007.
} 
En este último sentido se ha entendido que "el principio de proporcionalidad, reformado o no, puede jugar un papel relevante como complemento a los criterios que la AEPD exige para entender como legal una determinada práctica de control"60.

\subsubsection{Posibilidad de limitar el control y uso que se efectúa con el GPS}

Hasta este punto, se puede obtener como primera idea que las soluciones planteadas por la doctrina parten del supuesto que la instauración del GPS como instrumento de control debe tener como objetivo y finalidad indagar si se ha realizado o no la labor encomendada, no siendo plausible, en principio, realizar un control sobre la persona del trabajador.

Relacionado con ello, debe tenerse en cuenta lo expresado para otro supuesto de control. Así por ejemplo, en cuanto a la vigilancia electrónica y la doctrina de suplicación que ha quedado sentada por los Tribunales, se ha expresado que "la vigilancia debe recaer sobre la actividad laboral -o la que debería ser su actividad laboral- quedando proscrita la utilización de cámaras o sistemas de audio destinados a cualquier finalidad distinta del control de la prestación de servicios de los trabajadores" 61 .

Siendo ello así, podría plantearse la siguiente afirmación (aunque no muy técnica), utilizando los mismos conceptos: "mientras una máquina (GPS) controle a una máquina (cochelcamión/móvil), no cabría plantear mayores dudas; el problema estaría en si a la persona del trabajador se le da un tratamiento de máquina..."62.

Delimitado el alcance de la vigilancia patronal, la solución que se plantea en este punto avanza un paso más. En efecto, a lo que se apunta dice relación con el uso que se le dará a la información que se obtiene con el GPS. En este escenario se encuentra el caso citado en párrafos anteriores, respecto al "sindicato de transportistas (que) acordó con la UPS que se utilizara el GPS solo para hacer un seguimiento de los envíos y no para controlar la disciplina de los trabajadores"63, puesto que existe un acuerdo expreso para clarificar los límites al control empresarial.

Esta posibilidad constituye una novedosa técnica de defensa del trabajador, la cual debiese ser plasmada en los respectivos convenios colectivos ${ }^{64}$.

60 PÉrez del Prado, D. “¿Puede... (n. 33), p. 17.

61 Sempere Navarro, A. V. y San Martín Mazzuccono, C., op. cit. (n. 1), p. 137.

62 Pudiese relacionarse esta afirmación con lo planteado por LANDSBERGIS, P., op. cit. (n. 49), p. 39. El autor recalca la importancia de no perder de vista que el trabajador, en su condición de ser humano, merece un tratamiento como tal, y no simplemente como un medio más de los factores productivos. Así, expresa que "en los últimos 50-60 años se han sugerido una variedad de métodos para reducir el estrés de los trabajadores. Existen muchos nombres: "gestión de recursos humanos de alto nivel de participación”, "organización del trabajo de alto rendimiento", "concepto de equipo", "producción modular", etc. Todos se basan en la premisa de que los trabajadores no deben ser tratados como máquinas, sino que se debe valorar su conocimiento".

63 Por LANDSBergis, P., op. cit. (n. 49), p. 41. En el mismo sentido, Gruber, J., op. cit. (n. 48).

64 Interesante es lo expresado en el informe elaborado por Andrew Bibby para UNI Sindicato Global, en el que se da a conocer lo ocurrido en Canadá, señalándose que: "el Canadian Unión of Postal Workers (CUPW) advirtió a sus miembros que siguiesen muy de cerca la iniciativa de Canadá Post de introducir ordenadores vinculados con GPS en varios centenares de furgonetas. Controlan (vía GPS) la ubicación de cada furgoneta, y también si el motor está en marcha, si el vehículo está en movimiento y si es el caso a qué velocidad y si las puertas están cerradas. Canadá Post dijo al sindicato que su objetivo era permitir a los supervisores saber si los chóferes conducen como es debido y si siguen las directrices de seguridad (mediante los 
De momento, y en esta parte, cabe reforzar la idea de que el trabajador pueda impedir la utilización por el empresario de la información recogida por el GPS con fines disciplinarios $^{65}$. Esta alternativa, limita por un lado la actividad intrusiva, pero no resuelve el problema de fondo.

En dicho sentido, se ha señalado que:

"esta medida serviría para paliar, únicamente, de manera parcial el problema ya que el empresario, aunque no utilice con aquellos fines todos los datos a su disposición sobre la prestación del trabajador, seguramente los tendrá en cuenta y en muchos casos serán decisivos a la hora de decidir sobre la cambios de funciones, movilidad geográfica, promociones, es decir, sobre aspectos relevantes de la vida profesional del trabajador en la empresa" 66 .

\subsubsection{Reforzamiento de la negociación colectiva, y en su defecto, protocolos}

Relacionado con el punto anterior, surge el espacio idóneo para la negociación colectiva como el medio por el cual los actores sociales involucrados, a falta de normativa laboral especial, regulen aquellas situaciones conflictivas sobre las que se requiere cierta certeza en cuanto a la extensión y uso que se realizará con el GPS y la información que este arroje.

Así, por ejemplo, cabría la posibilidad de reglamentar apagar el móvil que contiene el GMS una vez finalizada la jornada laboral, o en ciertas pausas de trabajo. En el mismo sentido, y para el caso de que la prestación laboral sea cumplida fuera del recinto de la empresa, cabría organizar de manera clara cuáles son las obligaciones y responsabilidades a las que se encuentra sujeto el trabajador. Asimismo, cabría la posibilidad de consensuar que la información emanada del GPS no pueda utilizarse para fundamentar acciones disciplinarias.

De hecho, la doctrina, tratando el tema de la incorporación de las nuevas tecnologías en el seno laboral (contexto genérico al supuesto que estamos ahora analizando), se ha mostrado a favor de normar este nuevo tipo de conflictos y desafíos, vía la autonomía colectiva. En ese sentido, se ha señalado que:

llamados "informes de excepción" generados por ordenador). El CUPW invocó el convenio colectivo actual con Canadá Post para asegurar que este control no se use a fines disciplinarios.

"La cláusula del convenio colectivo del CUPW con Canadá Post que cubre la vigilancia establece que en ningún momento estos sistemas (de vigilancia y de observación) deberán utilizarse como medio para evaluar el rendimiento de los empleados ni para reunir pruebas en apoyo de medidas disciplinarias, a no ser que estas medidas deriven de la perpetración de un acto criminal”". Bibby, A. "Te están siguiendo". Artículo elaborado para UNI Sindicato Global. Disponible en http://www.andrewbibby. com/pdf/Surveillance-es.pdf (Última consulta realizada el 3 de diciembre de 2011).

65 Si bien excede los fines de este trabajo, cabe señalar la trascendencia (en lo que se refiera a los riesgos psicosociales) de tener claridad del marco que regulará las relaciones laborales. Así, se ha expresado que "tener claras las reglas del juego en la relación laboral contribuye a disipar posibles situaciones de ansiedad. Es importante que el trabajador tenga identificado de dónde emanan las decisiones que le afectan y hasta dónde pueden llegar las mismas. Estamos hablando del ejercicio del poder organizativo que compete al empresario y que la negociación colectiva regula con profusión, si bien no siempre desde una perspectiva acorde con la prevención de riesgos, y menos con la prevención de riesgos psicosociales". CHARRO BAENA, P. y SAN MarTín MAZZUCCONI, C. "Otros factores de riesgo psicosociales”; en: SAN MARTín MAZZUCCONI, C. (Dir.). El tratamiento convencional de los riesgos psicosociales. Estado actual y nuevas propuestas. Secretaría de Salud Laboral de la UGT-CEC, 2010.

66 Cardona RuberT, M. B., op. cit. (n. 9), p. 74. 
"la ausencia de una regulación escrita y específica por parte de la ley diseña un escenario especialmente propicio para que entre en juego la negociación colectiva. El convenio colectivo, de hecho, tiene en su mano la posibilidad de despejar sectorialmente las habituales dudas acerca de la materia que nos ocupa, declarando expresamente los límites del correcto uso de los medios tecnológicos por los trabajadores y por sus representantes y de los poderes empresariales de dirección y vigilancia" ${ }^{\prime}$.

Teniendo presente esta idea, podría afirmarse que por medio de la regulación en el convenio colectivo, se lograría un actuar de buena fe entre las partes contratantes, puesto que desde un inicio quedará claro cuál es el contexto en el que estas deben desenvolverse. Y ello, no solo en lo referido a la incorporación de mecanismos de GPS en los instrumentos de trabajo, sino de las consecuencias que ello traerá a la forma en que debe ser cumplida la prestación.

A falta de lo anterior, lo aconsejable pudiese ser que este tipo de materias se encuentre regulado en Protocolos de Actuación fijados de forma unilateral por el empleador. En atención a lo prescrito en el artículo 20.3 del ET no resultaría arbitrario el que el empresario regule las normas de actuación de este medio de control, ya que no se requeriría el consentimiento de los trabajadores.

Es más, la jurisprudencia del Tribunal Supremo, para el supuesto de la revisión de ordenadores, ha expresado que es legítimo este tipo de normativa, puesto que lo injustificado e improcedente sería aplicar consecuencias jurídicas cuando no ha quedado claro cuáles serán las reglas de juego ${ }^{68}$. En efecto, en un fallo reciente en esta materia, expresó:

"lo que debe hacer la empresa de acuerdo con las exigencias de buena fe es establecer previamente las reglas de uso de esos medios -con aplicación de prohibiciones absolutas o parciales- e informar a los trabajadores de que va existir control y de los medios que han de aplicarse en orden a comprobar la corrección de los usos, así como de las medidas que han de adoptarse en su caso para garantizar la efectiva utilización laboral del medio cuando sea preciso, sin perjuicio de la posible aplicación de otras medidas de carácter preventivo..." 69 .

\footnotetext{
67 Sempere Navarro, A. V. y San Martín Mazzuccono, C., op. cit. (n. 1), p. 35.

68 En esta parte cobra relevancia el tener las "reglas del juego" claras. Al respecto, dada su relevancia dogmática debe señalarse la reciente doctrina del Tribunal Supremo español en lo referido a las facultades empresariales sobre los computadores institucionales y el eventual uso extralaboral que pueda hacerse de este. Sobre el particular vid. la sentencia del TS fecha 6 de octubre de 2011 [Recurso 4053/2010].

Se ha expresado en relación a este pronunciamiento que "en aquellos supuestos en que las instrucciones de uso comunicadas a la plantilla prohíban taxativamente la utilización de los medios tecnológicos para actividades ajenas al trabajo, el empleador podrá controlar aun si de ello resulta su acceso a cuestiones de carácter estrictamente privado, pues habrá erradicado la expectativa de intimidad y secreto del trabajador", agregándose, "Aún queda sin embargo por solventar qué ocurre en aquellos casos en que la empresa no prohíbe tajantemente el uso privado del ordenador y demás instrumentos, sino que lo que prohíbe es un uso privado abusivo o ilícito". GUZMÁn, M. E. "El Supremo admite que la empresa controle el uso del ordenador por sus trabajadores aun cuando acceda a información privada”. Disponible en la siguiente dirección de Internet: http://www.diariojuridico.com/opinion/el-supremo-admite-que-la-empresa-controle-el-uso-del-ordenador-por-sus-trabajadores-aun-cuando-accedaa-informacion privada.html (Última consulta realizada el 31 de diciembre de 2011).

69 STS 8 marzo 2011 (RJ 2011, 932).
} 
Por lo anterior, lo más aconsejable sería tener fijado desde un inicio el marco de actuación, usos y funciones que pueda hacerse con la información que proporciona el GPS, así como también la responsabilidad del trabajador en el mantenimiento para el buen funcionamiento de este medio de control. En este sentido, la jurisprudencia judicial ha resaltado la importancia de esta regulación.

Un caso en este sentido, se refiere a la instalación de un dispositivo GPS por parte del empleador, en el vehículo de la empresa, hecho que no era de conocimiento del trabajador ${ }^{70}$.

A falta de conocimiento y noticia de esta situación, evidentemente tampoco se reguló cómo se ejercería el control por parte del empresario, teniendo en especial consideración que este se prestaba en distintas ciudades.

El hecho conflictivo se produce ante un desfase entre los partes de trabajo emitido por el trabajador y la información propiciada por el GPS, lo cual motivó que el empleador procediera al despido de este último.

Por ello, el trabajador recurre a la justicia solicitando la declaración de improcedencia del despido. Llegado el proceso a conocimiento del TSJ, este razonó de la siguiente forma:

"Ciertamente la empresa puede controlar el cumplimiento de la jornada. Ahora bien, de la misma forma que se puede servir de mecanismos de control está obligada, cuando menos, a indicar con precisión y claridad a sus trabajadores qué es lo que estos deben cumplir..., máxime cuando la jornada no se desarrolla en la forma habitual. Quien pretende exigir un cumplimiento estricto, debe aplicar el mismo criterio estricto para comunicar e informar lo que debe ser cumplido, en todos sus aspectos". Agregando posteriormente: "Lo que no es admisible es que el empresario aplique un doble criterio para medir: uno estricto para exigir el cumplimiento y otro laxo para informar de las obligaciones".

Regulando desde un comienzo esta situación, se evitaría la existencia de lagunas o vacíos en esta materia.

\subsubsection{Complemento salarial}

Una de las formas en que se puede traducir el acuerdo al que lleguen las organizaciones sindicales y empresariales reside en la incorporación al convenio colectivo respectivo de un plus de nuevas tecnologías aplicable para aquellos trabajadores que realicen la prestación contratada con instrumentos de trabajo que contengan incorporados GPS o GMS. Este acuerdo podría aplicarse, a su vez, para aquellos trabajadores que si bien no cumplen el trabajo encomendado con el dispositivo al que se encuentra adosado la nueva tecnología, tienen la obligación de portar dicho mecanismo para mantener un contacto constante con su empleador o la empresa.

Pese a que existen otras posibles soluciones, esta resulta quizás la más llamativa. Fundamentalmente porque lo que pretende este mecanismo es restablecer el equilibrio entre las partes, el cual resulta quebrantado en la medida que se incorpora a la relación laboral un

70 STSJ Madrid 13 octubre 2009 (AS 2009, 2930). 
medio de control extremamente intenso, y en algunos casos intrusivos. Todo ello sin perjuicio de la acentuación del poder de control empresarial que dicho medio conlleva.

Esta intensidad del poder de observación del empleador, implica un mayor riesgo para el trabajador y una mayor diligencia de este, por lo que atendido a criterios de equidad, correspondería recibir una contraprestación por la responsabilidad de este mayor riesgo para el dependiente. De lo contrario, el único beneficiario con la incorporación de esta nueva tecnología, sería el empleador. Las razones de equidad tienen sentido puesto que el Derecho del Trabajo nace ante la constatación fáctica de una desigualdad entre el empleador y el trabajador, de manera que resulta imprescindible dotar de cierta protección a este último.

Por lo demás, no debe olvidarse que esta rama del ordenamiento jurídico es un instrumento de equilibrio entre los derechos de los trabajadores y el poder de dirección del empresario, por lo que la regulación de este tipo de acuerdos no es más que la aplicación operativa de este principio, al intentar equiparar esta asimetría, sin que sea demasiado gravoso para una de las partes contratantes ${ }^{71}$.

Así, por ejemplo, puede mencionarse un caso tramitado ante la jurisdicción social ${ }^{72}$.

El asunto trata de la solicitud de un grupo de trabajadores que a falta de regulación en el convenio de empresa y de sector, demandaron la procedencia de este plus. Las razones de esta alegación radicaban en la decisión empresarial de modificar las condiciones en que se efectuaba la prestación de servicios incorporando, entre otros cambios, la instalación de un ordenador con GPS al camión recolector (se trataba de una empresa dedicada a la recogida de residuos sólidos).

La sentencia de instancia acoge la petición efectuada por los trabajadores y declara la procedencia de percibir un plus de nuevas tecnologías por cada día trabajado, puesto que debe compensarse económicamente la modificación producida ${ }^{73}$.

El TSJ, conociendo del recurso de suplicación intentado por la empresa, lo acoge, no obstante efectúa el siguiente razonamiento de interés en esta parte del estudio:

"Ahora bien, tales circunstancias -se refiere a la ausencia de regulación en el convenio colectivo de empresa y del sector, así como la no existencia de norma pactada y legal que sustente la petición de los actores- no determinan sin más, que deba desestimarse la demanda puesto que, admitido el cambio operado en la prestación de servicios de los conductores de camiones de carga lateral, debe examinarse si se ha producido un desequilibrio dentro del pacto inicial, susceptible de ser compensado económicamente, mediante la aplicación de la cláusula de mayor onerosidad de la prestación, sin

\footnotetext{
71 Montoya Melgar, A. "Libertad de empresa y poder de dirección del empresario en las relaciones laborales", en: SÁNChez Trigueros, C. y González Díaz, F. (Dirs.). Libertad de Empresa y Poder de Dirección del Empresario en las Relaciones Laborales. Estudios ofrecidos al profesor Alfredo Montoya Melgar. Pamplona, España: Aranzadi, 2011, p. 29.

72 STSJ Cantabria 5 de octubre 2009 (AS 2009, 2483).

73 El TSJ, hace mención a la instancia laboral expresando: "La sentencia de instancia, después de considerar que las modificaciones operadas en el desarrollo de la prestación de servicios de estos trabajadores, no constituyen una modificación sustancial de las condiciones laborales, considera sin embargo, que la modificación introducida debe compensarse económicamente, al suponer la asunción de nuevas funciones que exceden del ámbito del art. 22 del convenio del sector y para cuantificar dicha compensación, considera adecuado el importe solicitado (8 euros), al ser semejante al plus de carga lateral y frontal reconocido en otros convenios de empresas".
} 
que por ello, podamos situarnos en el ámbito de un conflicto de intereses, ya que en este sentido, la sentencia del Tribunal Supremo de 5.3.2008 (RJ 2008, 3484) recogiendo los postulados de la STC 11/1981 (RTC 1981, 11), ha reconocido la posibilidad de reclamar "una alteración del convenio" en aquellos casos en los que se haya producido "un cambio absoluto y radical de las circunstancias que permitan aplicar la llamada cláusula rebus sic stantibus"... la modificación operada carece de la relevancia necesaria para determinar un desequilibrio en las iniciales obligaciones de las partes susceptible de generar un derecho a la compensación económica que se reconoce en la instancia, máxime cuando además, como ya se apuntó, ni el convenio de empresa ni el del sector, regulan un plus semejante al que se postula y sin que pueda acudirse a la normativa pactada en otras empresas distintas a las que nos ocupa, para vincular dicho abono".

Resulta interesante el que ambas partes puedan pactar y regular la forma que se incorporarán las innovaciones tecnológicas en el proceso productivo de la empresa, puesto que esto constituye un reconocimiento explícito de que este tipo de hechos resulta de una trascendencia (atendida la posible lesión de derechos del trabajador) de tal envergadura sobre el cual debe existir un consenso entre trabajadores y empleador. Junto a ello, y atendido al desequilibrio que implica la admisión de este nuevo escenario, parece de justicia el pactar bonos o pluses que intenten recomponer las situaciones jurídicas al estado en que se encontraban con anterioridad a esta decisión.

\section{IDEAS FINALES}

I. En el ordenamiento jurídico español no existe un listado taxativo de instrumentos o medidas de indagación que se encuentren prescritos. Por el contario, se vuelve a la regla general de recalcar que estas no pueden importar un menoscabo a la dignidad del trabajador.

El problema jurídico que ello plantea en la actualidad, a falta de un listado concreto o genérico de herramientas de control prohibidas, consiste en determinar cuándo un nuevo sistema de indagación empresarial cumple ese estándar constitutivo de intrusivo o vulneratorio de los derechos fundamentales del trabajador. presario.

II. El GPS y GSM puede constituir una herramienta de control al servicio del em-

En concreto, este adelanto científico permite determinar la ubicación casi exacta de un determinado objeto, planteándose la controversia de si este poder de observación y conocimiento empresarial está en armonía con el respeto a la intimidad del asalariado.

Sin lugar a dudas, esta herramienta acentúa el poder de control patronal al implicar que el trabajador que la utiliza esté permanente vigilado y contralado, permitiendo con ello tener noticia de los movimientos que realiza el trabajador, llamando a aquello como la monitorización permanente. 
III. Con la utilización desmesurada de este sistema, se haría casi ilusorio el establecimiento de un espacio reservado e íntimo para el trabajador, ya que si por ejemplo el dispositivo se encuentra adosado a un móvil que este debe portar es perfectamente posible determinar qué lugares o sitios visitó aquel, en la medida que sería imposible dividir el historial del instrumento de trabajo de los movimientos que realiza el portador de este.

Pero no solo ello. Tal y como ha avanzado la tecnología, cabe plantearse la interrogante de qué ocurriría si el sistema no solo se encuentre incorporado en coches, camiones o teléfonos móviles, sino en otras herramientas de trabajo o artefactos que debe portar el trabajador, hipótesis quizás más graves que la realidad actual.

IV. Con este adelanto científico ya no se ejerce un control a distancia por parte del empleador, cuestión por lo demás, absolutamente legítima y vigente. Por el contario, en el caso de un uso ilimitado del GPS como mecanismo de indagación, el control va con el trabajador, lo sigue por donde quiere que este vaya, al igual como lo sería que este cargara sobre sus hombros con una mochila.

Ante ese escenario, cabría preguntarse entonces ¿hay "libertad" en las acciones que realiza el trabajador, y, por ende, una protección a la intimidad, cuando se tiene el temor fundado de que acciones personales (lugares que se visita o frecuenta) puedan llegar a ser conocida por otra persona?

Piénsese que ante esta hipótesis el trabajador se vería conminado a dar explicaciones de por qué se encontraba en esos lugares, situación que desde ya afecta la intimidad, entendida esta como una posibilidad de autodeterminación, y por qué no decirlo, de no ser cuestionado e interrogado -mientras no exista un interés público que lo justifique- de las acciones realizadas en su tiempo libre ${ }^{74}$.

\footnotetext{
74 Clarificador y sumamente actual es lo expresado por Ugarte Cataldo, J. L., quien se refiere a la intimidad, atendiendo a sus dos posibles acepciones jurídicas, como derecho al secreto y como autonomía. En este último sentido, expresa: "La otra dimensión de la privacidad es entenderla, además, como autonomía”.

En este caso, como se ha destacado, corresponde al derecho a adoptar decisiones respecto de la propia vida sin la injerencia de terceros -derecho general de autonomía-. Es, para decirlo en forma sencilla, el ideal del autogobierno.

Así, "cuando hablamos de privacidad pensamos, a un tiempo, en dos cosas, o que se nos excluya -según la fórmula de Sartrede la mirada de los otros (privacidad como intimidad), o que, en cambio, nuestra voluntad cuente respecto de nosotros mismos y respecto de los demás y que nos constituya como sujetos (privacidad como autonomía)".

Por ello, mientras una exige opacidad, la otra supone todo lo contrario: visibilidad. Y en esa perspectiva, ambas dimensiones de la privacidad tienen sentido para el trabajador y sirven para moldear la relación entre ese derecho y el poder empresarial. Mientras la privacidad como secreto le permite al trabajador mantener en la opacidad aspectos de su vida, denegando el acceso al panóptico empresarial, la privacidad como autonomía le permite al trabajador algo muy distinto: constituirse como sujeto propio y único, visibilizando su peculiar e individual percepción del mundo ante un espacio social tensionante a dicha visibilización, como es la empresa. UGARTE CATALDO, J. L. "Privacidad, trabajo y derechos fundamentales", en: Estudios Constitucionales, No 1, año 9, p. 17. Talca, Chile: Centro de Estudios Constitucionales, Facultad de Ciencias Jurídicas y Sociales, Universidad de Talca.

En sentido similar TASCÓN LÓPEZ, R., "Sobre la evolución... (n. 10), p. 8. "Quien se sabe así vigilado pierde, evidentemente, las más elementales capacidades de organizar el trabajo propio con unos mínimos márgenes de iniciativa y queda sometido a una presión difícilmente soportable, capaz de poner en peligro evidente su propio equilibrio físico-psíquico (lo cual, pone en cuestión alguna de las más elementales obligaciones de protección inherentes al contrato de trabajo, ex art. 14 LPRL), forzándole, en último término, a cambiar de forma radical su conducta para tratar de adaptarla al standard del controlador del rendimiento".
} 
Teniendo ello presente pudiera concluirse que el GPS (incluyendo en tal concepto al GMS) como un mecanismo de control empresarial, utilizado de forma ilimitada se traduciría en una vigilancia total, permanente, indiscriminada y absoluta de las actividades que realiza el trabajador a lo largo de toda su jornada laboral -incluyendo, también, sus pausa de trabajo-, corriendo un serio riesgo la intimidad del trabajador, derecho fundamental del que este es titular no obstante su ingreso a la empresa.

Compartimos en este aspecto las reflexiones de Rodríguez Escanciano quien expresa que:

"un control tan exhaustivo y permanente que llegue a acabar con cualquier resquicio de intimidad y autonomía en el lugar de trabajo supondría situar el poder de vigilancia en una dimensión inhumana, capaz de poner en peligro no solo la libertad y la dignidad del trabajador, sino también su propio equilibrio psíquico, y de elevar el poder empresarial al grado de "omnipotente, anónimo e invisible"”75.

V. Todas las soluciones propuestas en este breve artículo apuntan en la misma dirección: lo que debe ser controlado es el cumplimiento de la labor encomendada y no las conductas del trabajador.

Dicha idea es primordial, por cuanto validar mecanismos de vigilancia permanente, constantes e ilimitados sobre la persona del trabajador no se corresponde con un Estado democrático promotor de derechos y libertades de sus ciudadanos.

En efecto, permitir este tipo de acciones sin limitación de ningún tipo sería un retroceso hacia estados anteriores a los que nos encontramos, puesto que a pretexto de una mayor flexibilidad en la ejecución de los servicios podría esconderse un control total, que abarcaría incluso a la propia persona del trabajador y a sus derechos fundamentales.

\section{BIBLIOGRAFÍA}

AGUT GARCíA, C. "Las facultades empresariales de vigilancia y control sobre útiles y herramientas de trabajo y otros efectos de la empresa”, en: GARCía NinET, J. I. (Dir.) y DE ViCEnTE PACHÉs, F. (Coord.). El control empresarial en el ámbito laboral. Valencia, España: CISS, 2005, p. 124.

Alarcón CARACUEl, M.R. "La informatización y las nuevas formas de trabajo". en: AA.VV. AlarCón CARACUel, M.R. y Esteban Legareta, R. (Coords.). Nuevas tecnologías de la información y la comunicación y Derecho del Trabajo. Bomarzo, 2004, p. 15.

Bibby, A. “Te están siguiendo”. Artículo elaborado para UNI Sindicato Global. Disponible en http://www.andrewbibby.com/pdf/Surveillance-es.pdf (Última consulta realizada el 3 de diciembre de 2011).

CARdona Rubert, M. B. Informática y contrato de trabajo. Valencia, España: Tirant lo Blanch, 1990.

Charro Baena, P. y SAN Martín Mazzucconi, C. "Otros factores de riesgo psicosociales", en: SAN MARTín MAZZUCCONI, C. (Dir.). El tratamiento convencional de los riesgos psicosociales. Estado actual y nuevas propuestas. Secretaría de Salud Laboral de la UGT-CEC, 2010.

DE ViCEnTE PACHÉs, F. "Las facultades empresariales de vigilancia y control en las relaciones de trabajo: Concepto y Fundamento. Una primera aproximación a las diversas formas de control empresarial”, en: Tribuna social: Revista de seguridad social y laboral No 157, p. 20. España, 2004.

75 Rodríguez Escanciano, S., op. cit. (n. 41), p. 99. 
FARriols i SOlA, A. "Introducción”, en: AA.VV. La protección de datos de carácter personal en los centros de trabajo. Madrid (Cinca), 2006, p. 33.

FERnÁNDEZ GARCÍA, A. "Sistemas de geolocalización como medio de control del trabajador: un análisis jurisprudencial”, en: Aranzadi, vol. 2, No 17, p. 4. España, 2010.

FERnÁNDez Villazón, L. A. Las facultades empresariales de control de la actividad laboral. Pamplona, España: Aranzadi, 2003, p. 87.

García, L.; Pozo Ruz, Ana; Ribeiro, A; Sandoval, F.; García-Alegre, M. C. "Sistema GPS: descripción análisis de errores, aplicaciones y futuro”, en: Mundo electrónico, No 306, p. 54. España, 2000.

GOÑI SEIN, J.L. "Controles empresariales: geolocalización, correo electrónico, internet, videovigilancia y controles biométricos", en: Justicia Laboral. Revista de Derecho del Trabajo y de la Seguridad Social, No 39, p. 21. España, 2009.

GOÑI SEIN, J. L., La videovigilancia empresarial y la protección de datos personales. Pamplona, España: Thomsom Civitas, 2007.

GRUBER, J. “Monitoring and the mobile workforce”. Artículo disponible en Internet en la siguiente dirección: http://workrights.us/wp-content/uploads/2011/02/gpsaba.pdf (Última consulta realizada el 26 de julio de 2011).

GuZMÁn, M. E. "El Supremo admite que la empresa controle el uso del ordenador por sus trabajadores aun cuando acceda a información privada”. Disponible en la siguiente dirección de Internet: http://www. diariojuridico.com/opinion/el-supremo-admite-que-la-empresa-controle-el-uso-del-ordenador-porsus-trabajadores-aun-cuando-acceda-a-informacion privada.html. (Última consulta realizada el 31 de diciembre de 2011)

LANDSBERGIS, P. “¿Qué se debe hacer para prevenir los riesgos psicosociales en el trabajo?”, en: Archivos de prevención de riesgos laborales, vol. 11, No 1, p. 41. España, 2008.

Mercader Ugina, J. R. "Derechos Fundamentales de los trabajadores y nuevas tecnologías: ¿hacia una empresa panóptica?”, en: Relaciones Laborales, No 10, 2001, p. 667.

Montoya Melgar, A. "Libertad de empresa y poder de dirección del empresario en las relaciones laborales", en: SÁnchez Trigueros, C. y GonzÁlez Díaz, F. (Dirs.). Libertad de Empresa y Poder de Dirección del Empresario en las Relaciones Laborales. Estudios ofrecidos al profesor Alfredo Montoya Melgar. Pamplona, España: Aranzadi, 2011, p. 29.

Pérez de los Cobos Orihuel, F. Nuevas tecnologías y relación de trabajo. Valencia, España: Tirant lo Blanch, 1990.

PÉREZ DEL PRADO, D. “¿Puede el empresario controlar a sus trabajadores mediante dispositivos GPS? Algunas notas sobre el cómo, el dónde y el porqué”, en: Información Laboral. Jurisprudencia No 10, p. 12. Espaกิa, 2009.

PÉREZ DEL PRADO, D. "Instrumentos GPS y poder de control del empresario", en: Revista de la contratación electrónica, No 107, p. 51. España, 2009.

PUCH, C. Nuevo Manual de GPS. Introducción al sistema global de posición. Madrid, España: Desnivel, 2005 , p. 9.

RODRÍGUEZ ESCANCIANO, S. "Vigilancia y control en la relación de trabajo: La incidencia de las nuevas tecnologías". En: AA.VV. La protección de datos de carácter personal en los centros de trabajo. Madrid (Cinca), 2006, p. 97.

SANPEDRO GULlON, V. "Facultades empresariales de vigilancia y control en los centro de trabajo", en: GARCÍA Ninet, J. I. (Dir.) y DE VICENTE PACHÉS, F. (Coord.). El control empresarial en el ámbito laboral. Valencia, España: CISS, 2005, p. 100.

Selma Penalva, A. "El control de acceso por medio de huella digital y sus repercusiones prácticas sobre el derecho a la intimidad de los trabajadores”, en: Aranzadi Socia: Revista Doctrinal, vol. 3. España, 2010. 
Selma Penalva, A. "Las peculiaridades prácticas del control en la empresa”, en: Anales de Derecho, No 27, p. 96. España: Universidad de Murcia, 2009.

Sempere Navarro, A. V. y SAn Martín Mazzuccono, C. Nuevas tecnologías y relaciones laborales. Pamplona, Madrid: Aranzadi, 2002.

TASCÓN LÓPEZ, R. "Sobre la evolución de los límites del poder tecnológico de control empresarial en el caso español”, en: IX Congreso Europeo de Derecho del Trabajo y de la Seguridad Social. Friburgo, Alemania, 16-19 de septiembre de 2008. Artículo disponible en http://kongress-und-kommunikation.com/html/ img/pool/Round_table_1_RodrigoLopez.pdf (Última consulta realizada el 30 de diciembre de 2011).

TASCÓN LÓPEZ, R. "El lento (pero firme) proceso de decantación de los límites del poder de control empresarial en la era tecnológica”, en: Aranzadi, № 17, 2007, p. 3.

Ugarte Cataldo, J. L. "Privacidad, trabajo y derechos fundamentales", en: Estudios Constitucionales, No 1, año 9, p. 17. Talca, Chile: Centro de Estudios Constitucionales, Facultad de Ciencias Jurídicas y Sociales, Universidad de Talca. 